\title{
Shallow Precipitation Detection and Classification Using Multifrequency Radar Observations and Model Simulations $\mathscr{a}$
}

\author{
MAlarvizhi ARULraj AND ANA P. BARRos \\ Duke University, Durham, North Carolina
}

(Manuscript received 28 March 2017, in final form 8 June 2017)

\begin{abstract}
Detection of shallow warm rainfall remains a critical source of uncertainty in remote sensing of precipitation, especially in regions of complex topographic and radiometric transitions, such as mountains and coastlines. To address this problem, a new algorithm to detect and classify shallow rainfall based on space-time dual-frequency correlation (DFC) of concurrent W- and Ka-band radar reflectivity profiles is demonstrated using ground-based observations from the Integrated Precipitation and Hydrology Experiment (IPHEx) in the Appalachian Mountains (MV), United States, and the Biogenic Aerosols-Effects on Clouds and Climate (BAECC) in Hyytiala (TMP), Finland. Detection is successful with false alarm errors of $2.64 \%$ and $4.45 \%$ for MV and TMP, respectively, corresponding to one order of magnitude improvement over the skill of operational satellite-based radar algorithms in similar conditions. Shallow rainfall is misclassified $12.5 \%$ of the time at MV, but all instances of low-level reverse orographic enhancement are detected and classified correctly. The classification errors are $8 \%$ and $17 \%$ for deep and shallow rainfall, respectively, in TMP; the latter is linked to reflectivity profiles with dark band but insufficient radar sensitivity to light rainfall $\left(<2 \mathrm{~mm} \mathrm{~h}^{-1}\right)$ remains the major source of error. The potential utility of the algorithm for satellite-based observations in mountainous regions is explored using an observing system simulation (OSS) of concurrent CloudSat Cloud Profiling Radar (CPR) and GPM Dual-Frequency Precipitation Radar (DPR) during IPHEx, and concurrent satellite observations over Borneo. The results suggest that integration of the methodology in existing regime-based classification algorithms is straightforward, and can lead to significant improvements in the detection and identification of shallow precipitation.
\end{abstract}

\section{Introduction}

The space-time variability of hydrometeors in convective precipitation shows high variability in vertical and horizontal structures typically with distinct deep cores of heavy rainfall and broad drop size distributions (DSD) in contrast with narrow DSDs for stratiform rainfall (Houze 1993; Zafar and Chandrasekar 2004). Independently of precipitation regimes, DSDs can change significantly with height over time because of changes in the surrounding environment and drop-drop interactions, including coalescence and break-up dynamics (e.g., Prat et al. 2008). In regions where spatially persistent multilayer cloud systems and fog banks form, seeder-feeder interactions modify rainfall at low levels, such as in the case of reverse orographic enhancement in the Southern Appalachians

Supplemental information related to this paper is available at the Journals Online website: http://dx.doi.org/10.1175/JTECHD-17-0060.s1.

Corresponding author: Ana P. Barros, barros@duke.edu
(Wilson and Barros 2014, 2015, 2017). Seeder-feeder interactions refer to the accelerated growth of raindrops produced by high-level clouds (seeders) as they fall through multilayer cloud systems, coalesce with low-level cloud and fog drops (feeders), resulting in a significant increase in raindrop sizes near the ground and, consequently, significant increases in surface precipitation.

The measured precipitation radar reflectivity factor $Z_{\lambda, m}$ at wavelength $\lambda$ and range $R$ is a nonlinear function of the equivalent reflectivity factor $Z_{\lambda, e}$ and the specific attenuation $k_{\lambda}$ :

$$
\begin{aligned}
Z_{\lambda, m}(R) & =Z_{\lambda, e}(R) \exp \left[-0.2 \ln (10) \int_{0}^{R} k_{\lambda}(s) d s\right], \\
Z_{\lambda, e}(R) & =\frac{\lambda^{4}}{\pi^{5}\left|K_{w}\right|^{2}} \int_{0}^{\infty} N(D, R) \sigma_{\lambda, b}(D, R) d D \\
k_{\lambda}(R) & =\int_{0}^{\infty} N(D, R) \sigma_{\lambda, e}(D, R) d D
\end{aligned}
$$

where $\sigma_{\lambda, b}$ and $\sigma_{\lambda, e}$ are the backscattering and extinction cross sections, respectively, of hydrometeors of diameter 
size $D ; N(D, R)$ is the DSD of rainfall at range $R$; and $\left|K_{w}\right|^{2}=0.93$ for water. The received power $P_{\lambda}(R)$ can be calculated using the generalized radar equation $\left[P_{\lambda}(R) \approx C Z_{\lambda, m}(R) / R^{2}\right]$, where the radar constant $C$ varies directly with range resolution $\Delta R$ and inversely with $\lambda^{2}$. The reflectivity factors $Z_{\lambda, e}$ and $k_{\lambda}$ vary nonlinearly with wavelength, hydrometeor size distribution, and rainfall rate (Liao et al. 2014; Marzano et al. 2003).

Reflectivity profiles of radars operating at short wavelengths differ from long wavelength radars as a result of differences in attenuation and scattering behavior as the concentration of non-Rayleigh scattering particles changes with wavelength (Kollias et al. 2007). Strong attenuation and large non-Rayleigh scattering artifacts for moderate and heavy intensity precipitation, typically associated with a high number of large raindrop sizes, constrain the use of millimeter-wave radars (e.g., W band) in monitoring clouds and light rainfall (Kollias et al. 2007; Mead et al. 1996). For example, in the lower $6 \mathrm{~km}$ of the troposphere, attenuation of the CloudSat Cloud Profiling Radar (CPR; $94 \mathrm{GHz}, \mathrm{W}$ band) signal is much stronger than for the Tropical Rainfall Measurement Mission Precipitation Radar (TRMM PR; $13.8 \mathrm{GHz}, \mathrm{Ku}$ band); conversely, the TRMM PR misses the anvil part of the cloud system (Sindhu and Bhat 2013). Because differences in the structure of reflectivity profiles at distinct frequencies result from specific precipitation structure features, combining and contrasting multifrequency radar observations should help to overcome their independent disadvantages (Fig. 1). This approach could be particularly useful to leverage Global Precipitation Measurement Dual-Frequency Precipitation Radar (GPM DPR, centimeter wavelength) and CloudSat CPR (millimeter wavelength) observations, including upcoming satellite missions [e.g., the European Space Agency's Earth Clouds, Aerosol and Radiation Explorer (EarthCARE)].

In the absence of physics-based models, operational precipitation retrievals from satellite-based observations such as the TRMM PR and the GPM DPR rely on DSD parameterizations that vary according to rainfall regime (e.g., convective or stratiform; Iguchi et al. 2000; Short and Nakamura 2000). Rainfall regime detection and classification are therefore a key step in the retrieval work flow prior to rainfall estimation proper (see section S1 of the supplemental material for a review of existing rainfall classification strategies developed for TRMM and GPM precipitation retrieval algorithms). Orographic processes and/or precipitation regimes in regions of complex topographic transitions are not explicitly addressed in operational algorithms because of the complex microphysics of orographic precipitation coupled to high spatial and temporal variability in a precipitation structure modulated by topography
(Barros et al. 2000; Houze 2012). Precipitation retrievals in mountainous regions consequently exhibit large detection errors $(\sim 50 \%)$ and severe underestimation of precipitation rates (e.g., Barros 2013; Prat and Barros 2010). Further, Duan et al. (2015) showed that, independent of rainfall intensity, large errors and uncertainty in TRMM PR rainfall estimates in the southern Appalachian Mountains (SAM) exhibited diurnal and seasonal patterns linked to spatial and temporal patterns of light and shallow orographic rainfall. This behavior is expected in complex terrains generally (e.g., Barros et al. 2000).

In this manuscript, a new algorithm to detect and identify shallow precipitation using collocated radars operating at two distinct wavelengths (i.e., centimeter vs millimeter) is presented. The algorithm, referred to as the shallow rain detection and classification algorithm (SRDC), relies on an integrated measure of the spacetime correlation between the reflectivity profiles, and is demonstrated and evaluated using specifically $\mathrm{W}$ - and Ka-band ground-based radars from monitoring sites in different climatic regions with distinct terrain complexity (Fig. 1a). Note that the algorithm formulation presented here should be applicable to any pair of frequencies with significant contrast in attenuation and scattering behavior (e.g., millimeter vs centimeter wavelengths), such as, for example, $\mathrm{W}$ and $\mathrm{Ku}, \mathrm{X}$, or $\mathrm{C}$ bands; the focus here is on $\mathrm{W}$ and $\mathrm{Ka}$ bands because of ground validation data availability.

The algorithm was implemented first using observations at Maggie Valley (MV), North Carolina, during the intensive observing period of the Integrated Precipitation and Hydrology Experiment (IPHEx IOP) from 1 May 2014 to 15 June 2014 in SAM (Barros et al. 2014). The second demonstration is for Hyytiala, Finland (ARM-TMP), a relatively flat region of terrain crisscrossed with many land-water boundaries, during the Biogenic Aerosols-Effects on Clouds and Climate (BAECC) field campaign from February through September (Petäjä 2013). An independent evaluation was conducted using ground-based radar data from the Atmospheric Radiation Measurement Southern Great Plains (ARM SGP) site in Oklahoma (described in section S2 of the supplemental material), a region without salient topographic or coastline contrasts. For proof of concept and to examine the potential generalization and application of the algorithm to satellite-based observations, the SRDC algorithm is applied to observing system simulations (OSS) of nearly concurrent GPM and CloudSat overpasses on 15 May 2014 during IPHEx (Fig. 1b), and to GPM DPR and CloudSat CPR observations along a complex terrain transect in Borneo (Fig. 1c). 
(a)

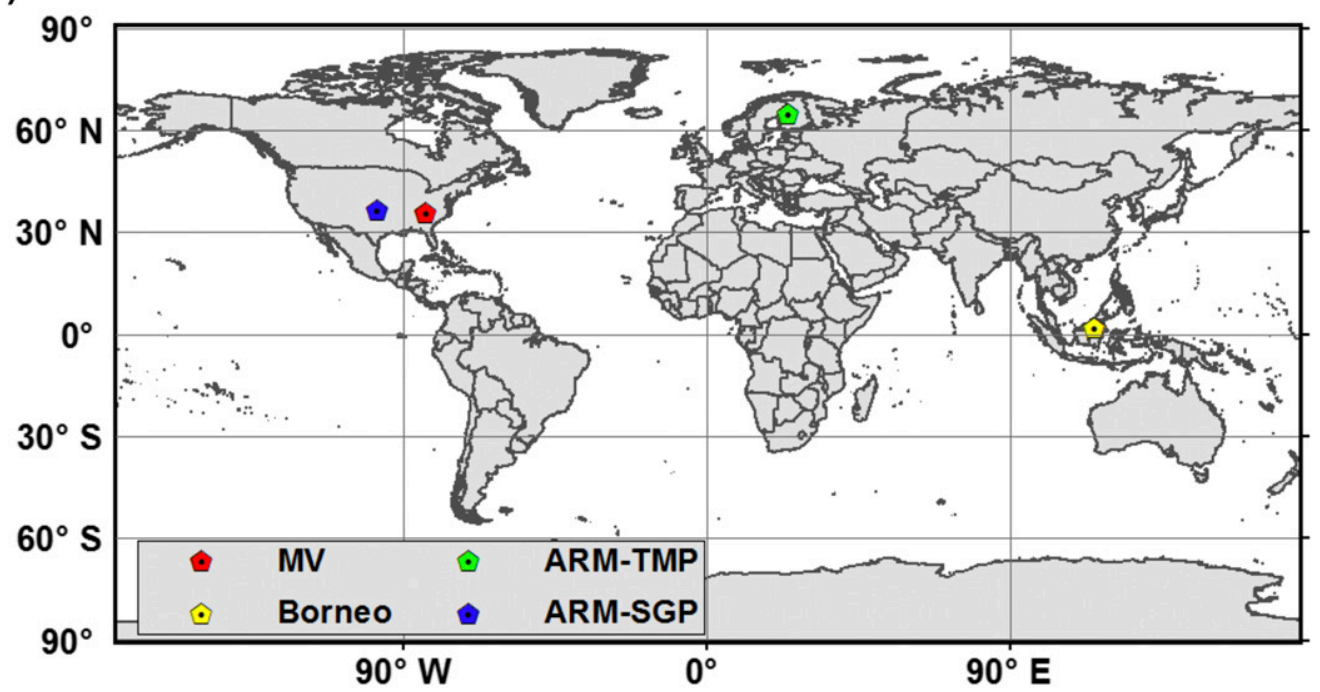

(b)

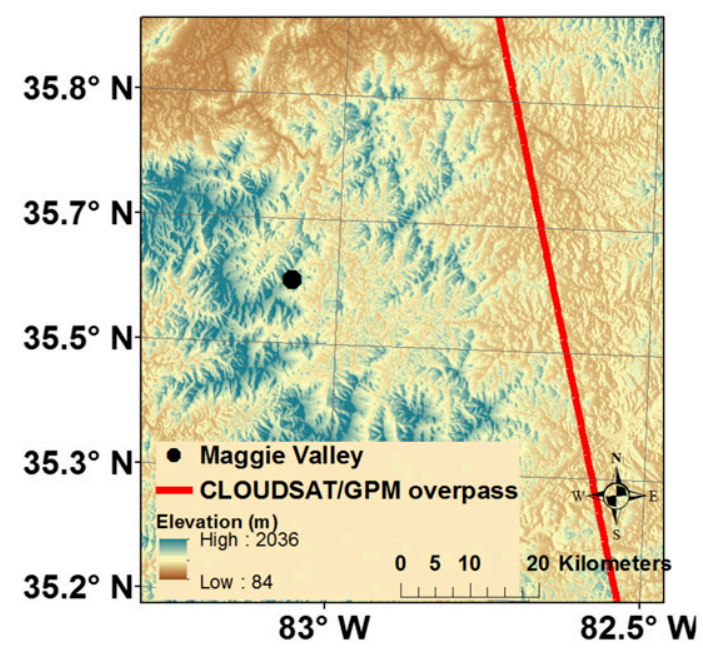

(c)

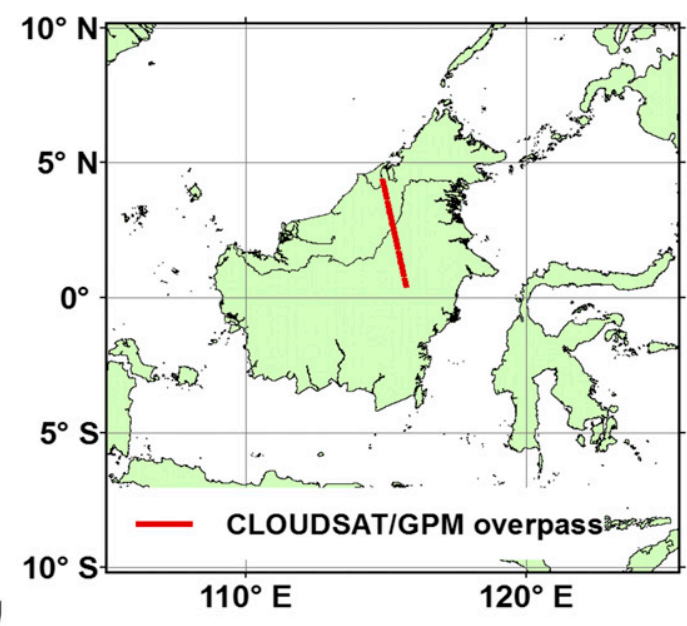

FIG. 1. (a) Map showing the locations where the SRDC algorithm was tested. Concurrent GPM DPR and CloudSat CPR overpass for (b) 15 May 2014 event during IPHEx used for the G-SDSU simulations and (c) 3 Jun 2014 event over Borneo.

The organization of the manuscript is as follows. Section 2 describes the data and instruments employed in locations such as MV and ARM-TMP. Section 3 presents the algorithm formulation followed by results and statistical analysis of the accuracy of the SRDC algorithm in section 4 , and a summary and conclusions are given in section 5 .

\section{Data description}

\section{a. $M V$}

The IPHEx IOP was conducted between 1 May 2014 and 15 June 2014 over the southeastern United States with collocated instruments installed at $\mathrm{MV}\left(35.5198^{\circ} \mathrm{N}\right.$, $83.0947^{\circ} \mathrm{W}$ ), including a scanning W-band dualpolarization radar, a Micro Rain Radar (MRR), an all-sky imager (ASI), a ceilometer, and an OTT Parsivel disdrometer (Barros et al. 2014, Figs. 1a and 1b). The W-band radar operates at $95 \mathrm{GHz}$ in a vertically pointing mode with a $0.25^{\circ}$ beamwidth and a minimum detectable threshold of $-55 \mathrm{dBZ}$ at $1 \mathrm{~km}$. The range resolution is $25 \mathrm{~m}$, where the vertical range extends from $475 \mathrm{~m}$ to $8.4 \mathrm{~km}$. The data acquisition rate ranges from 1 to $2 \mathrm{~s}$; however, data utilized in the analysis are aggregated to 1-min temporal resolution. The MRR operates at $24 \mathrm{GHz}$ (K band) with minimum detectable reflectivity of $-5 \mathrm{~dB} Z$ and $1.5^{\circ}$ beamwidth in vertically 
pointing mode to measure the profiles of Doppler power spectra. It was set up with a vertical resolution of $50 \mathrm{~m}$ with range extending to a maximum height of $1.5 \mathrm{~km}$, and the measurements were aggregated to 1-min temporal resolution. The equivalent reflectivity factor obtained from the MRR is used for the analysis with negative values reset to zero. The OTT Parsivel ${ }^{2}$ is a laser-based optical disdrometer that simultaneously measures the particle size and velocity of the raindrops with a temporal resolution of $10 \mathrm{~s}$, and thus records the number of raindrops and rain intensity. The formulation and implementation of the SRDC algorithm is informed by past research, including comprehensive analysis of collocated MRR and Parsivel observations in the SAM (e.g., Prat and Barros 2010; Wilson and Barros 2014).

\section{b. ARM-TMP}

The ARM Mobile Facility (AMF2) was installed in a Scots pine forest at TMP (Fig. 1a) from February 2014 until mid-September 2014 during the BAECC field campaign. The objective was to measure biogenic aerosols from forests and to study aerosol-cloud-precipitation interactions and climate impacts (Petäjä 2013). Various instruments were collocated at the ARM TMP site, including the marine W-band ARM cloud radar (MWACR), the Ka zenith-pointing ARM radar (Ka-ZR), a ceilometer and a two-dimensional video disdrometer (2DVD). The MWACR operates at $95 \mathrm{GHz}$ in zenith-pointing mode, and the data were aggregated to 1-min temporal resolution. The radar was deployed at an elevation of $160 \mathrm{~m}$ above mean sea level (MSL), and the vertical range of the reflectivity profiles extended from $210 \mathrm{~m}$ to $18.2 \mathrm{~km}$. The Ka-ZR is a 35-GHz zenith-pointing Doppler radar with a data acquisition rate of approximately $1 \mathrm{~s}$, deployed at an altitude of $180 \mathrm{~m}$ MSL. The vertical range of data extended from $500 \mathrm{~m}$ to $18 \mathrm{~km}$. Data are available from the Ka-ZR in general and moderate sensitivity modes. The general mode detects full range but is less sensitive; the moderate sensitivity mode is a compromise between sensitivity and range, and thus the moderate sensitivity data are used here for analysis (Feng et al. 2014). The range resolution of the MWACR and $\mathrm{Ka}-\mathrm{ZR}$ is approximately $30 \mathrm{~m}$. The 2DVD comprises two orthogonally aligned video cameras to record the hydrometeor size distribution, fall velocity, geometry, and precipitation properties. The 2DVD data have a temporal resolution of $1 \mathrm{~min}$, and the 2DVD rain rate was used for evaluating the algorithm.

\section{c. GPM DPR and CloudSat CPR Goddard SDSU simulations}

The Goddard Satellite Data Simulator Unit (G-SDSU; Matsui et al. 2013) simulates satellite observations based on atmospheric conditions generated by a numerical weather prediction (NWP) model [e.g., Weather Research and Forecasting Model (WRF)]. Here, G-SDSU GPM DPR and CloudSat CPR simulations of the 15 May 2014 event during IPHEx previously studied by Wilson and Barros $(2015,2017)$ are examined in detail. Note that the spatial resolution of both G-SDSU GPM DPR and CloudSat CPR simulations is $1.25 \mathrm{~km}$, which is different from the spatial resolution of the standard CPR $(1 \mathrm{~km})$ and DPR $(5 \mathrm{~km})$ products. Further, the CloudSat CPR G-SDSU simulation output is on a three-dimensional grid; the GPM DPR G-SDSU simulation output is on a two-dimensional grid with the vertical profiles aligned along the satellite overpass (single swath). The grid points with the closest spatial coordinates between the CloudSat CPR and the GPM DPR G-SDSU swaths were identified for analysis in section 4. Previous studies of CloudSat CPR G-SDSU simulations reported that it overestimates reflectivity profiles for heights above $4 \mathrm{~km}$ but that the overall macrostructure of the observations is captured well (Tao et al. 2009).

\section{d. GPM DPR and CloudSat CPR Observations}

The GPM DPR is a spaceborne Earth-pointing precipitation radar on board the GPM satellite and operates in the $\mathrm{Ku}$ band $(13.6 \mathrm{GHz})$ and $\mathrm{Ka}$ band $(35.5 \mathrm{GHz})$. The $\mathrm{Ka}$ band is tuned for high sensitivity to detect light precipitation and snow events up to $65^{\circ}$ latitude. Both the GPM Ku and Ka bands operate with a beamwidth of $0.71^{\circ}$ with nominal minimum measurable rain rates (reflectivity) of $0.5 \mathrm{~mm} \mathrm{~h}^{-1}(18 \mathrm{dBZ})$ and $0.2 \mathrm{~mm} \mathrm{~h}^{-1}(12 \mathrm{dBZ})$ for the $\mathrm{Ku}$ and Ka bands, respectively (Iguchi et al. 2015; Hou et al. 2014). Ka-band radar reflectivity profiles from the DPR Level 2 products were used for analysis. The CloudSat CPR operates at $94 \mathrm{GHz}$ to detect and distinguish weakly scattered radiation from clouds at the global scale (Stephens et al. 2008). Reflectivity data from the CloudSat geometric profile product (2B-GEOPROF) are used here.

The CloudSat-GPM coincidence product (2BCSATGPM; including CloudSat CPR (W band), GPM DPR's Ku-band $(13.6 \mathrm{GHz})$ and Ka-band $(35.5 \mathrm{GHz})$ radar profiles, and the passive microwave brightness temperatures from the 13-channel (10-183 GHz) GMI radiometer for coincident CloudSat and GPM overpasses within $15 \mathrm{~min}$ of each other are utilized to extract nearly concurrent observations (Turk 2016). The minimum detectable radar reflectivity of CloudSat CPR is $-30 \mathrm{dBZ}$. The 2BCSATGPM products extract the nearest GPM DPR pixels that coincide with the CloudSat CPR track. Precipitation estimates for the concurrent CloudSat and GPM tracks extracted from the DPR Level 2A product [2ADPR, version 04A (2ADPR V04A)] include the precipitation rate from three swaths-normal scans (NS), matched scans (MS), and high-sensitivity scans 
(HS). The HS detect light precipitation in the near-nadir region (within $8.5^{\circ}$ angle; and with a swath width of $125 \mathrm{~km}$ ) with a minimum detectable reflectivity factor of $12 \mathrm{dBZ}$ $\left(0.2 \mathrm{~mm} \mathrm{~h}^{-1}\right.$ rain rate). The MS by the Ka-band radar have minimum detectable reflectivity of $18 \mathrm{dBZ}\left(0.5 \mathrm{~mm} \mathrm{~h}^{-1}\right.$ rain rate) with a swath width of $125 \mathrm{~km}$. The NS of the Kuband precipitation radar have a swath width of $245 \mathrm{~km}$ and a nominal minimum detectable reflectivity similar to that of MS, though Toyoshima et al. (2015) suggest that in practice the actual Ku-band radar NS detectability is $14.5 \mathrm{dBZ}$. Because of the differences in viewing geometry and resolution (Fig. 1 in Turk 2016), only the GPM DPR Ka-band HS, specifically the nadir-looking 2ADPR V04A product with all the CloudSat pixels aligned with the GPM DPR grid, are presented here, consistent with the groundbased cases.

\section{Shallow rain detection and classification algorithm}

\section{a. Vertical correlation structure calculations}

The SRDC algorithm detects the presence of precipitation and classifies precipitation features into shallow and deep structures. In this study, deep structure events are defined as 1 -min precipitation rates associated with reflectivity profiles exceeding reflectivity criteria above $5 \mathrm{~km}$ above ground level (AGL), whereas shallow precipitation events have reflectivity profiles exceeding reflectivity criteria below $5 \mathrm{~km}$. Note that this reference height (i.e., $5 \mathrm{~km}$ ) is expected to vary depending on regional precipitation physics and topography. As discussed earlier, the algorithm takes advantage of contrasts between radar measurements in the centimeter (e.g., Ka band) and millimeter (e.g., $\mathrm{W}$ band) wavelengths to extract information masking their respective operational disadvantages as illustrated in Fig. 2 (Kollias et al. 2007; Sindhu and Bhat 2013).

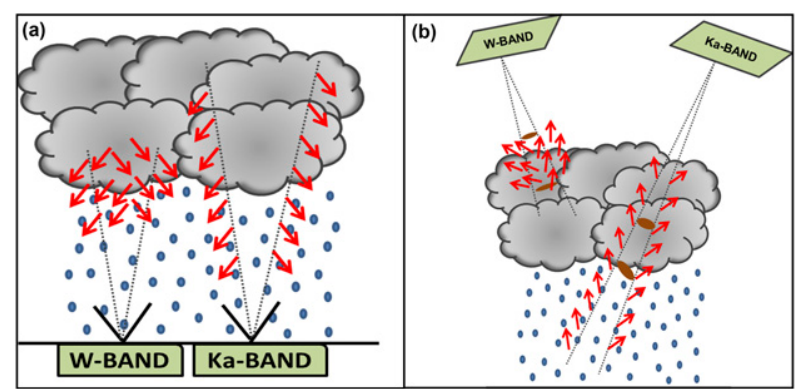

FIG. 2. Physical representation of the operating principle of (a) ground-based and (b) spaceborne radars operating at centimeter (Ka band) and millimeter ( $\mathrm{W}$ band) wavelengths.

Here, concurrent and collocated W-band ( $\mathrm{mm}$ ) and Ka-band $(\mathrm{cm})$ radars operating in vertically pointing mode are the basic inputs into the algorithm. The time resolution and period considered for analysis should be identical because the algorithm involves the calculation of the space-time correlation between the two bands. The data are averaged to a common temporal resolution of $1 \mathrm{~min}$. To leverage the dual-frequency observations, a two-pronged strategy is adopted: method 1 compares Ka-band profiles with W-band profiles over the entire vertical range of observations to identify the presence or absence (clear sky) of deep convective structures; method 2 captures all precipitation events, and it is used in conjunction with method 1 to identify shallow precipitation events. The work flow of the SRDC algorithm is illustrated in Fig. 3, and the formulation is detailed next.

Take the time-dependent reflectivity profiles $Z_{\mathrm{Ka}}\left(h_{\mathrm{Ka} 1}, t\right)$ and $Z_{\mathrm{W}}\left(h_{\mathrm{W} 2}, t\right)$ of Ka- and W- band radars, where $h_{\mathrm{Ka} 1}$ and $h_{\mathrm{W} 2}$ are vertical range bins of the Ka and $\mathrm{W}$ bands from the surface to maximum heights $z_{1}$ and $z_{2}$, respectively. First, the space-time correlation analysis between Kaand W-band radar reflectivity factors is performed to obtain a three-dimensional (3D) space-time correlation $\rho\left(h_{\mathrm{Ka} 1}, h_{\mathrm{W} 2}, t\right)$ as follows:

$$
\rho\left(h_{\mathrm{Ka} 1}, h_{\mathrm{W} 2}, t\right)=\frac{\sum_{k=0}^{N_{t}-1}\left[Z_{\mathrm{Ka}}\left(h_{\mathrm{Ka} 1}, t-k\right)-\overline{Z_{\mathrm{Ka}}\left(h_{\mathrm{Ka} 1}, t\right)}\right] \times\left[Z_{\mathrm{W}}\left(h_{\mathrm{W} 2}, t-k\right)-\overline{Z_{\mathrm{W}}\left(h_{\mathrm{W} 2}, t\right)}\right]}{\mathrm{SD}_{\mathrm{Ka} 1} \times \mathrm{SD}_{\mathrm{W} 2}},
$$

where $N_{t}$ is the length of the moving time window (the appropriate length of the time window is examined in section 4), and

$$
\overline{Z_{\mathrm{Ka}}\left(h_{\mathrm{Ka} 1}, t\right)}=\frac{\sum_{k=0}^{N_{t}-1} Z_{\mathrm{Ka}}\left(h_{\mathrm{Ka} 1}, t-k\right)}{N_{t}},
$$

$$
\begin{aligned}
\overline{Z_{\mathrm{W}}\left(h_{\mathrm{W} 2}, t\right)} & =\frac{\sum_{k=0}^{N_{t}-1} Z_{\mathrm{W}}\left(h_{\mathrm{W} 2}, t-k\right)}{N_{t}}, \\
\mathrm{SD}_{\mathrm{Ka} 1} & =\sqrt{\sum_{k=0}^{N_{t}-1}\left[Z_{\mathrm{Ka}}\left(h_{\mathrm{Ka} 1}, t-k\right)-\overline{Z_{\mathrm{Ka}}\left(h_{\mathrm{Ka} 1}, t\right)}\right]^{2}},
\end{aligned}
$$




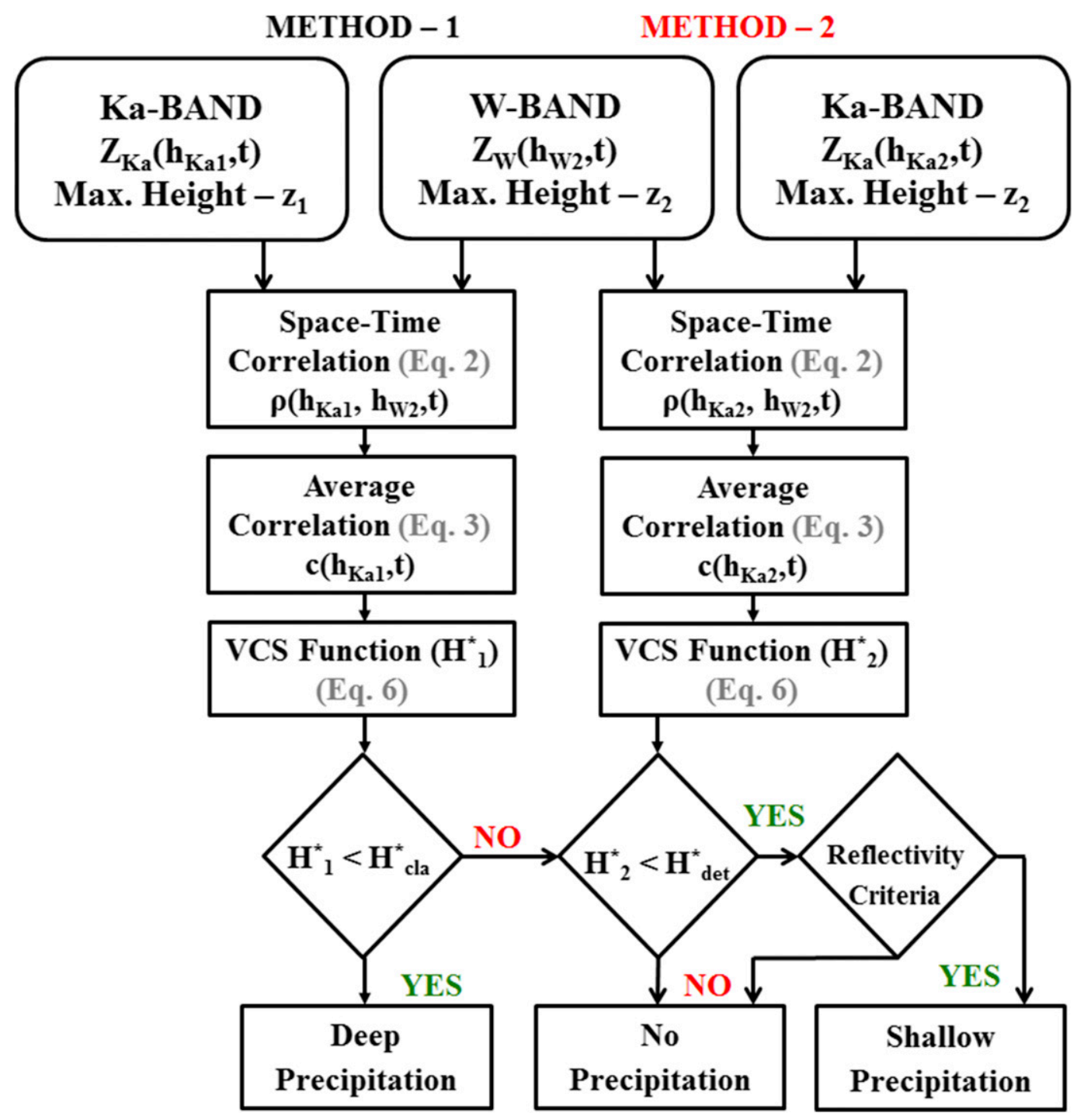

FIG. 3. Schematic representation of the SRDC algorithm. Algorithm input is the equivalent radar reflectivity from collocated W-band and Ka-band radars. The VCS thresholds for classification and detection are $H_{\text {cla }}^{*}$ and $H_{\text {det }}^{*}$, respectively.

$$
\mathrm{SD}_{\mathrm{W} 2}=\sqrt{\sum_{k=0}^{N_{t}-1}\left[Z_{\mathrm{W}}\left(h_{\mathrm{W} 2}, t-k\right)-\overline{Z_{\mathrm{W}}\left(h_{\mathrm{W} 2}, t\right)}\right]^{2}} .
$$

The 3D space-time correlation $\rho\left(h_{\mathrm{Ka} 1}, h_{\mathrm{W} 2}, t\right)$ is then averaged over the $\mathrm{W}$-band vertical range converting the $3 \mathrm{D}$ data into the $2 \mathrm{D}$ matrix $c\left(h_{\mathrm{Ka}}, t\right)$ :

$$
c\left(h_{\mathrm{Ka} 1}, t\right)=\frac{\sum_{j=1}^{N_{\mathrm{W} 2}} \rho\left[h_{\mathrm{Ka} 1}, h_{\mathrm{W} 2}(j), t\right]}{N_{\mathrm{W} 2}},
$$

where $N_{\mathrm{Ka} 1}$ and $N_{\mathrm{W} 2}$ are the number of height bins in the Ka- and W-band radar reflectivity profiles, respectively, within heights $z_{1}$ and $z_{2}$. At a generic time $t$, the average dual-frequency correlation (DFC) $c\left(h_{\mathrm{Ka} 1}, t\right)$ is a one- dimensional vertical function defined at the height of each bin, that is, a spatial series varying with height.

Changes in precipitation microphysics are captured differently in the reflectivity profiles at the two frequencies in the precipitation column, and therefore the DFC captures variations in the vertical structure of precipitation as a function of time. The height $z_{c}$ at which $c\left(h_{\mathrm{Ka} 1}, t\right)$ first becomes negative (the first zero crossing) is a robust estimate of the active depth of precipitation jointly detected by both radars. Note that the roles of Ka- and W-band reflectivity profiles are predicated on data availability over a vertical range suitable to quantify nonlinear attenuation differences between the two bands for the same vertical structure of precipitation. If the vertical range of the Ka-band radar is lower than that for 
the W-band radar, then their roles in Eqs. (2a-e) and (3) can be exchanged, albeit only for rainfall conditions that result in small to moderate attenuation at $\mathrm{W}$ band (light rainfall). This will be further discussed in section 4 .

Next, the variations observed in the structure of the correlation function are described quantitatively using a measure of the information content in each column of the DFC (Balestrino et al. 2007; Denis and Cremoux 2002). In particular, Denis and Cremoux (2002) successfully used the mean of the absolute value of the time derivative of a time series $X$ of length $\tau$ to identify nonstationarity as follows:

$$
H(\tau)=m_{\left|X^{\prime}\right|}=\sum_{\Delta t=0}^{\tau} \frac{|X(t+\Delta t)-X(t)|}{\tau} .
$$

Here, we are interested in spatial variability as a function of height $z$ defined along the reflectivity profile rather than a time series. Assuming the process is stationary, the function defined in Eq. (4) is applied instead to the DFC $c\left(h_{\mathrm{Ka} 1}, t_{0}\right)$ obtained from Eq. (3) [i.e., $X$ is replaced by $c\left(h_{\mathrm{Ka} 1}, t_{0}\right)$, where $t_{0}$ is the time representing the temporal window of width $N_{t}$ (i.e., $\tau=N_{t}$ ) used to estimate the space-time correlation in Eq. (2)]. The DFC varies from -1 to 1 , the integration length of the spatial series is the height $d$ of the Ka-band reflectivity profile $(\mathrm{km})$ [i.e., $d=N_{\mathrm{Ka} 1} \times \Delta z$, with radar bin resolution $\Delta z$ ], and thus the corresponding spatial metric $H_{s}$ is calculated as follows:

$$
\begin{aligned}
H_{s}\left(t_{0}\right) & =\frac{L\left(t_{0}\right)}{d}, \\
L\left(t_{0}\right) & =\sum_{i=1}^{N_{\mathrm{Ka} 1}-1}\left|c\left[h_{\mathrm{Ka} 1}(i+1), t_{0}\right]-c\left[h_{\mathrm{Ka} 1}(i), t_{0}\right]\right|,
\end{aligned}
$$

where $L\left(t_{0}\right)$ is the cumulative sum of the absolute average correlation differences along the Ka-band profile. Given the small range of variability of the DFC during a storm event, a logarithmic transformation is applied to Eq. (5a) aiming to enhance the sensitivity of $H_{s}$ by "stretching" $L\left(t_{0}\right)$ to detect small changes that can be attributed to changes in the vertical structure of precipitation processes. For a uniform spatial series, $H_{s}=0$ and the logarithmic of a zero function is not defined. To avoid this problem, a shift was introduced to $H_{s}$ so that when the DFC is constant, the modified metric is 1 . Finally, the form of the measure of the variability of the average vertical correlation structure (VCS) function $H^{*}$ for a generic time $t$ is

$$
\begin{aligned}
& H^{*}(t)=1+\log _{2}\left[\frac{L(t)}{d}\right]=\log _{2}\left[\frac{2 L(t)}{d}\right] \text { for } L \neq 0 \\
& H^{*}(t)=1 \text { for } L=0 .
\end{aligned}
$$

Note that $H^{*}(t)$ is tied to the specific length $N_{t}$ of the window used for temporal averaging in Eq. (2), and different window lengths should yield different VCS values.

\section{b. Precipitation detection and classification}

The reflectivity profiles are processed following the two work flow paths depicted in Fig. 3: method 1 (column VCS; $H_{1}^{*}$ ) applies to deep reflectivity profiles extending to cloud-top height (CTH; e.g., $z_{1}=8 \mathrm{~km}$ at MV); method 2 (shallow VCS; $H_{2}^{*}$ ) applies to low-level radar reflectivity profiles up to a height $z_{2}$ to capture changes in surface precipitation due to low-level processes (e.g., $z_{2}=1.5 \mathrm{~km}$ at MV). A reflectivity constraint is included for no-precipitation event cases to reduce noise artifacts. Specifically, minimum reflectivity thresholds of 12 and $0 \mathrm{dBZ}$ were used to detect precipitation for the Ka- and W- band radars, respectively, used in this study. Methods 1 and 2 follow the same steps except that the Ka-band (W band) reflectivity extends vertically to either CTH or $z_{1}\left(z_{2}\right)$. Note that $z_{1}, z_{2}$, and CTH vary from site to site depending on how the radars operate and thus data availability, and depending on local hydrometeorology (clouds and rainfall regimes). Operationally, a sliding (moving and overlapping) time window is used to detect and analyze short-duration precipitation. The "optimal" width of the sliding time window is extended to depend on the characteristic time scales of regional hydrometeorological processes.

The radar VCS functions using method $1\left(H_{1}^{*}\right)$ and/or method $2\left(H_{2}^{*}\right)$ show significant sensitivity to rainy versus nonrainy conditions, and for rainy conditions with precipitation structure, which can be verified against independent ground-based observations. The detection threshold $H_{\text {det }}^{*}$ is determined with a Bayesian classifier aiming to minimize the overlap of the VCS probability density functions (PDFs) for method 1 (no precipitation) and method 2 (precipitation). Similarly, the classification threshold $H_{\text {cla }}^{*}$ is determined to minimize the overlap of method 1 PDFs of $H_{1}^{*}$ for deep and shallow precipitation. These two thresholds are used subsequently to classify events based on reflectivity measurements alone: 1 ) deep precipitation if $\left(H_{1}^{*}<H_{\text {cla }}^{*}\right)$, else 2$)$ nonprecipitation conditions correspond to $\left(H_{2}^{*}>H_{\mathrm{det}}^{*}\right)$ and shallow precipitation otherwise. The application and evaluation of the algorithm for different hydrometeorological regimes are presented next.

\section{Results and discussion}

a. $M V$

The SRDC algorithm was developed initially for the IPHEx IOP MV site as described earlier. Figure 4 shows 


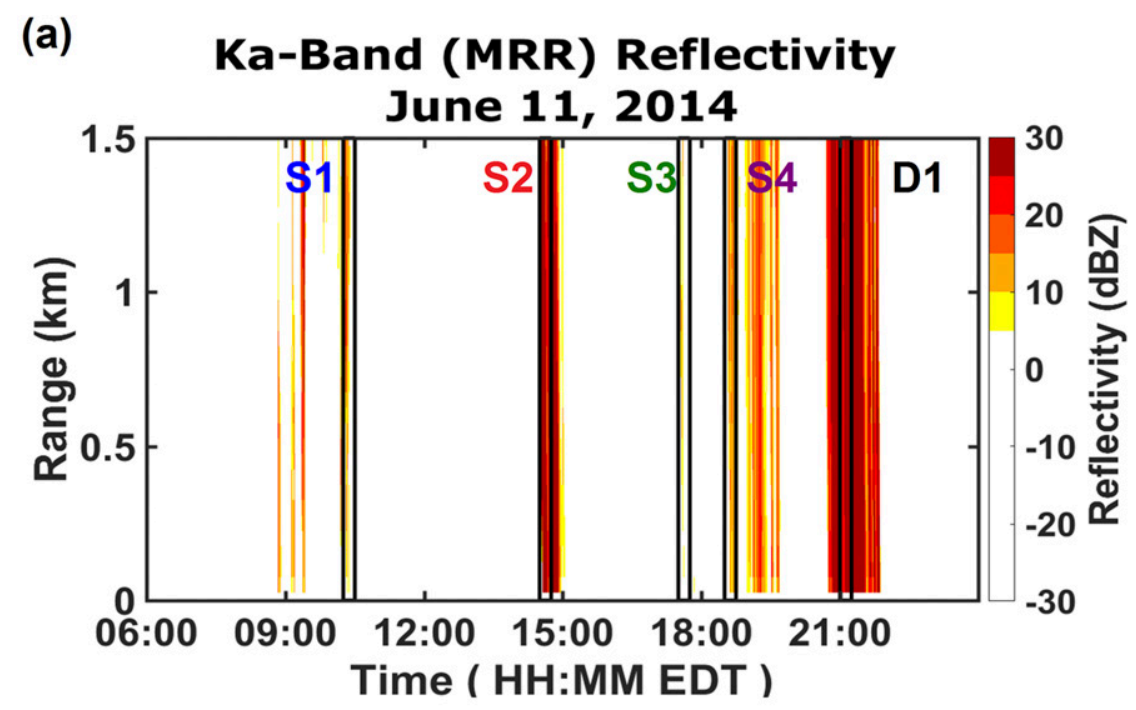

(b) ACHIEVE W-Band Reflectivity June 11, 2014

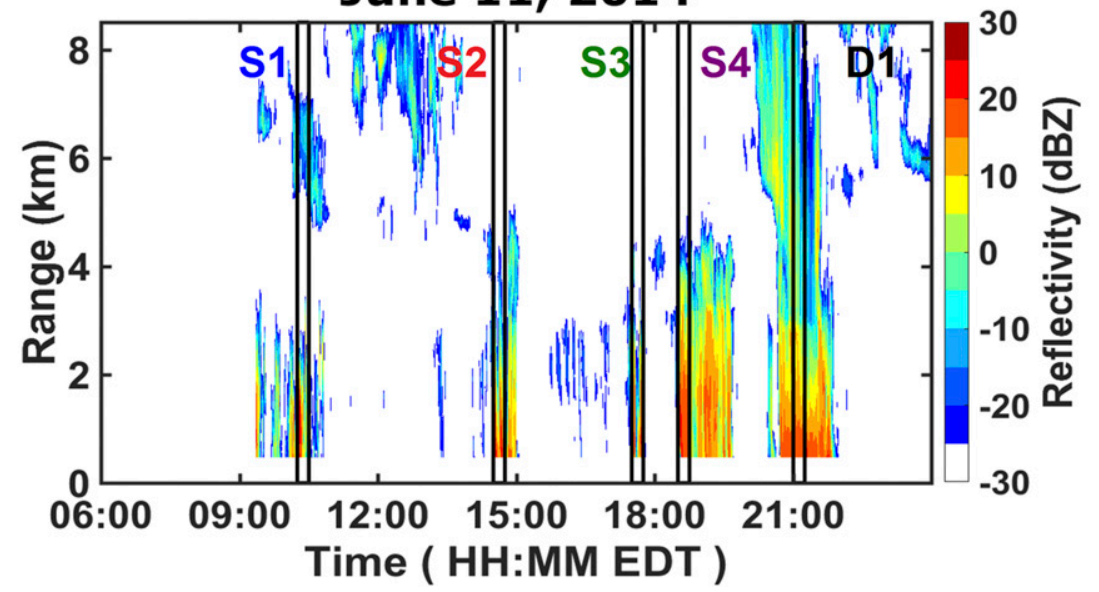

FIG. 4. Equivalent reflectivity factor of (a) MRR and (b) Aerosol, Cloud, Humidity, Interactions Exploring and Validating Enterprise (ACHIEVE) W-band radar observed at MV on 11 Jun 2014 during IPHEx IOP. Note that the MRR maximum level $(1.5 \mathrm{~km})$ is lower than the ACHIEVE W-band maximum level $(8 \mathrm{~km})$ as a result of the specific radar operational configuration. Five events ( $\mathrm{S} 1-\mathrm{S} 4$, and D1; black boxes) considered for analysis.

W-band radar and MRR reflectivity profiles on 11 June 2014. Intermittent precipitation activity was present throughout the day (from 1000 until 2200 LT) with shallow precipitation ahead of the convective rainfall after 2030 LT. The reflectivity profiles of the W-band radar and MRR distinctly show five events (S1, S2, S3, S4, and D1), where the first four events are shallow precipitation (S1: 1015-1030 LT, S2: 1430-1445 LT, S3: 1730-1745 LT, S4: 1830-1845 LT) and the last event corresponds to a deep structure (D1:2100-2115 LT). The DFC is computed between the W-band radar $\left(z_{1}=8 \mathrm{~km}\right)$ and $\operatorname{MRR}\left(z_{2}=1.5 \mathrm{~km}\right)$ reflectivity, and it is subsequently averaged over the MRR vertical profile range as shown in Fig. 5a. The method 1 average correlation shows high fluctuations around zero at higher levels after it first becomes negative at an altitude $z_{c}$ below $5 \mathrm{~km}$ in the case of shallow events (S1-S4); however, the method 1 average correlation structure is comparatively smooth for the deep structure event, D1, until it first becomes negative at an altitude above $8 \mathrm{~km}$.

The MRR's operational setup at MV prevents us from using the Ka band for column VCS calculations; instead, $\mathrm{W}$ band is used here though it suffers from severe attenuation for deep structure cases. This approach was 
(a)

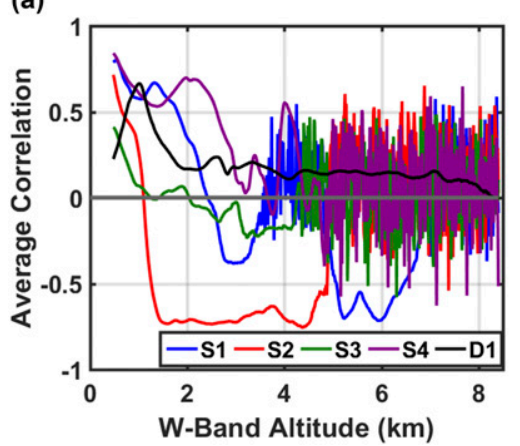

(b)

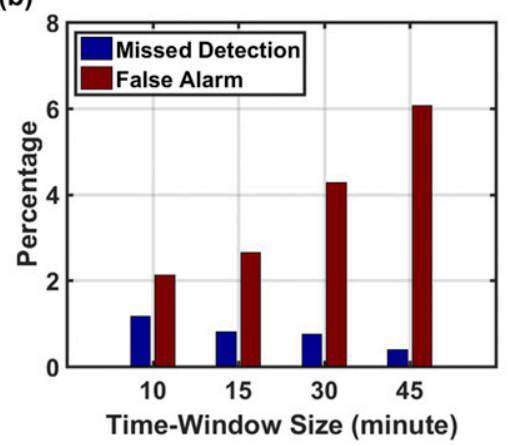

(c)

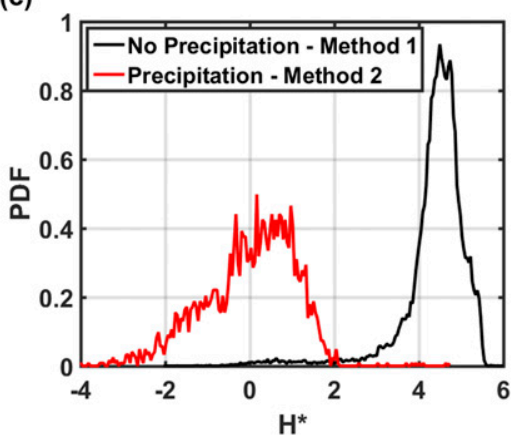

FIG. 5. (a) Average of the method 1 space-time correlation computed in step 2 of the SRDC algorithm for the five events highlighted in Fig. 4 (refer to section 4a). Changes in the pattern of the curve exhibit the evolution of D1 from S1-S4. (b) Trade-off between the MDR and FAR errors for varying time-window width. (c) PDF of the optimum (15 min) moving time window for the computation of VCS by the SRDC algorithm.

adopted after careful inspection of the adequacy of W-band observations, which revealed consistently deep and well-defined $\mathrm{W}$-band reflectivity profiles as a result of the high frequency of light and shallow precipitation in this region. Thus, interchanging the Ka- and W-band profiles is deemed acceptable at MV during IPHEx, and indeed generally if attenuation is small enough that there is information content through the active depth of precipitation as discussed in section 3 .

The SRDC algorithm was applied to all of the IPHEx IOP data from 1 May 2014 and 15 June 2015, comprehending 2738 rain events (1-min time scale) and 35693 min without rainfall. To determine the width for the moving time window, a sensitivity study of the PDF of precipitation occurrence using methods 1 and 2 for different time intervals of length $N_{t}$ was performed, with the time-averaged values posted at the end of the averaging window interval (i.e., $t_{0}$ ). The optimal window size (here, $15 \mathrm{~min}$ ) produces the best trade-off between the missed detection and false alarm (FA) errors as shown in Fig. 5b. Note the increase and decrease in the false alarm rate (FAR) and missed detection rate (MDR) as the width of the window increases. Figure 5c shows the PDF for the 15-min temporal width to highlight the missed detection (MD) and false alarm statistics. The percentage of MDR and FAR errors for a 15 -min window $\left(N_{t}=15\right)$ width are $0.8 \%$ and $2.64 \%$, respectively-the best compromise at MV. Method 1

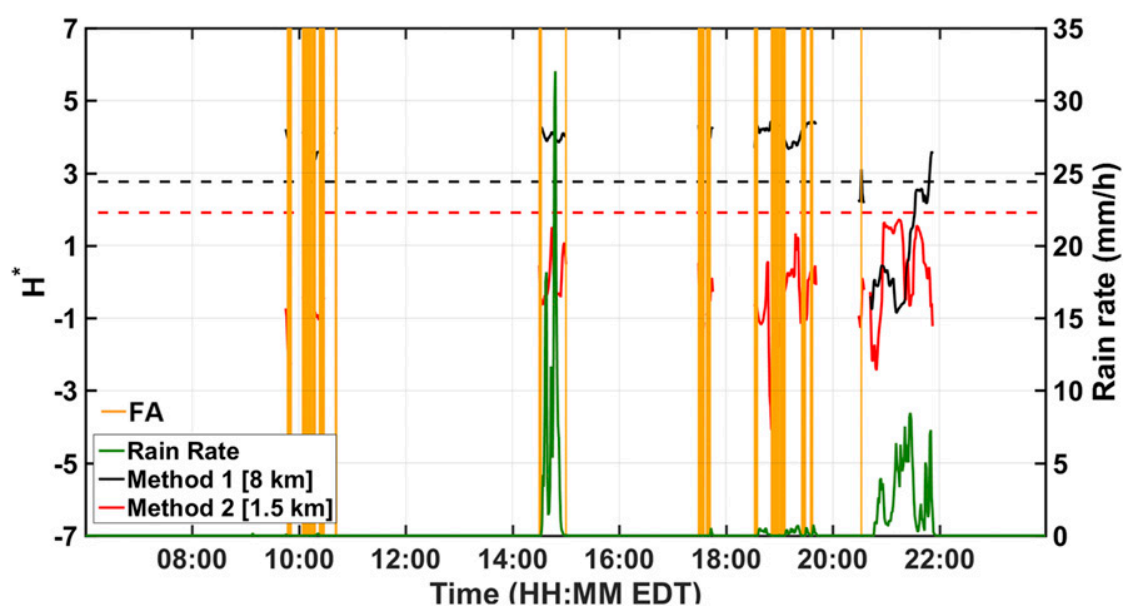

FIG. 6. VCS functions computed from SRDC methods 1 and 2 for the 11 Jun 2014 event compared with the rain-rate recorded by a Parsivel disdrometer collocated with the ACHIEVE W-band radar and MRR at MV. Threshold for precipitation detection (red dotted lines) and classification (black dotted lines). SRDC algorithm detects precipitation when $H_{2}^{*}$ (red solid line) is less than the detection threshold (red dotted horizontal line). FA occurrences (orange lines). SRDC algorithm classifies the event as deep when $H_{1}^{*}$ (black solid line) is less than the classification threshold (black dotted horizontal line). 
(a)

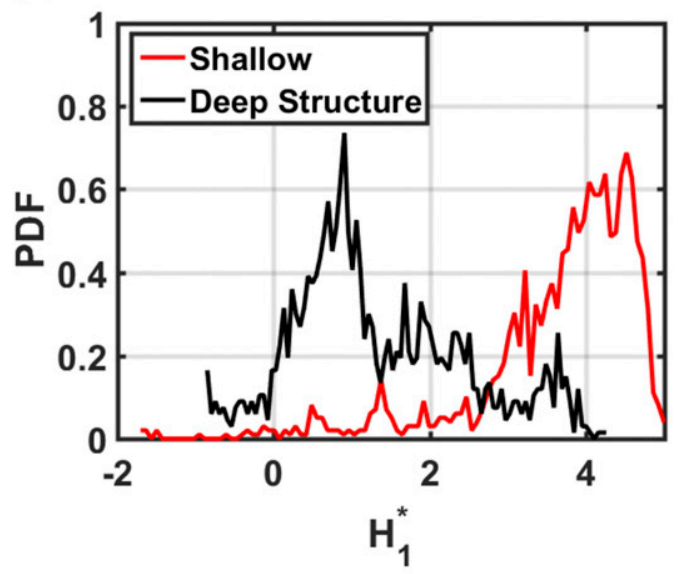

(b)

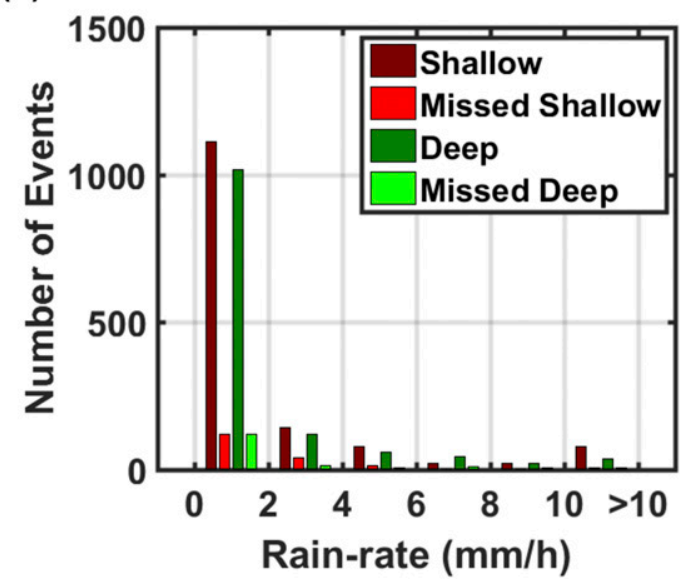

FIG. 7. (a) PDF of 15-min method 1 VCS for classification of precipitation events at 1-min time scale. (b) Histogram of detection skill for different deep and shallow precipitation classes as a function of precipitation intensity during IPHEx IOP (1 May-15 Jun 2014) at MV.

performs well for the no-precipitation cases as expected, whereas method 2 is skillful at detecting precipitation, therefore enabling, in combination with method 1 , the separation of deep and shallow events.

The performance of the algorithm with the 15-min moving window for 11 June 2014 is examined in detail next. The time series of VCS functions computed from method 1 and method 2, and the corresponding time series of the rainfall intensity recorded by the collocated Parsivel disdrometer are shown in Fig. 6. Green and pink dotted lines identify the precipitation detection and classification thresholds, respectively. Most of the precipitation events are detected by tracking the VCS function values, after applying the reflectivity threshold criteria. Column VCS $H_{1}^{*}$ and shallow VCS $H_{2}^{*}$ are higher than the precipitation detection threshold for noprecipitation conditions, whereas shallow VCS $H_{2}^{*}$ is lower than the detection threshold for precipitation events. For example, the algorithm detects the start of the D1 event $2 \mathrm{~min}$ in advance because of averaging artifacts, resulting in two false alarm counts. Similarly, method 1 VCS values above and below the classification threshold are identified as shallow and deep, respectively. Inspection of the PDFs of precipitation and no-precipitation cases detected by the algorithm (Fig. 5c) indicates that $H_{\mathrm{det}}^{*}=1.91$, the point of intersection between the two curves, is appropriate for rainfall detection.

The next step is to classify the precipitation events based on vertical structure. The PDFs of the VCS functions of shallow and deep structure events are shown in Fig. 7a, where $H_{\text {cla }}^{*}=2.76$ is the point of intersection. At $\mathrm{MV}$, the ambiguity in the classification of deep structure precipitation is $14.0 \%$, whereas for shallow or low-level rainfall the value is close to $12.0 \%$. The $H_{\mathrm{det}}^{*}$ and $H_{\mathrm{cla}}^{*}$ thresholds were used to differentiate between no-precipitation, deep, and shallow precipitation events over the duration of the IPHEX-IOP, and the corresponding contingency matrix is shown in Table 1. It is evident from Fig. 7b that many shallow events observed at MV during the IPHEx IOP had very high precipitation intensity compared to that of deep structure events. This is an indicator of the robustness of the algorithm that captures the reverse orographic enhancement effects associated with seeder-feeder interactions among stratiform rainfall, low-level clouds, and deep fog in the inner mountain region (Wilson and Barros 2014, 2015, 2017). The algorithm misses shallow precipitation events with rain rates less than $5 \mathrm{~mm} \mathrm{~h}^{-1}$, though most missed events are for rain rates less than $2 \mathrm{~mm} \mathrm{~h}^{-1}$ based on the disdrometer observations often not recorded by the collocated rain gauges, and thus approaching instrumental sensitivity. In addition, some misclassification errors result in part from temporal offsets at the beginning and ending of rainy periods, which can be addressed moving the windowed VCS

TABLE 1. Contingency table for precipitation detection and classification by SRDC methods 1 and 2 for profiles observed during IPHEX IOP at MV.

\begin{tabular}{llrcc}
\hline \hline & \multicolumn{3}{c}{ Classified as } \\
\cline { 3 - 5 } & & $\begin{array}{c}\text { Deep } \\
(\%)\end{array}$ & $\begin{array}{c}\text { Shallow } \\
(\%)\end{array}$ & $\begin{array}{c}\text { No precipitation } \\
(\%)\end{array}$ \\
\hline \multirow{2}{*}{ Actual } & Deep & 85.3 & 14.4 & 0.3 \\
& Shallow & 12.3 & 79.0 & 8.7 \\
& No precipitation & 4.0 & 2.6 & 93.4 \\
\hline
\end{tabular}



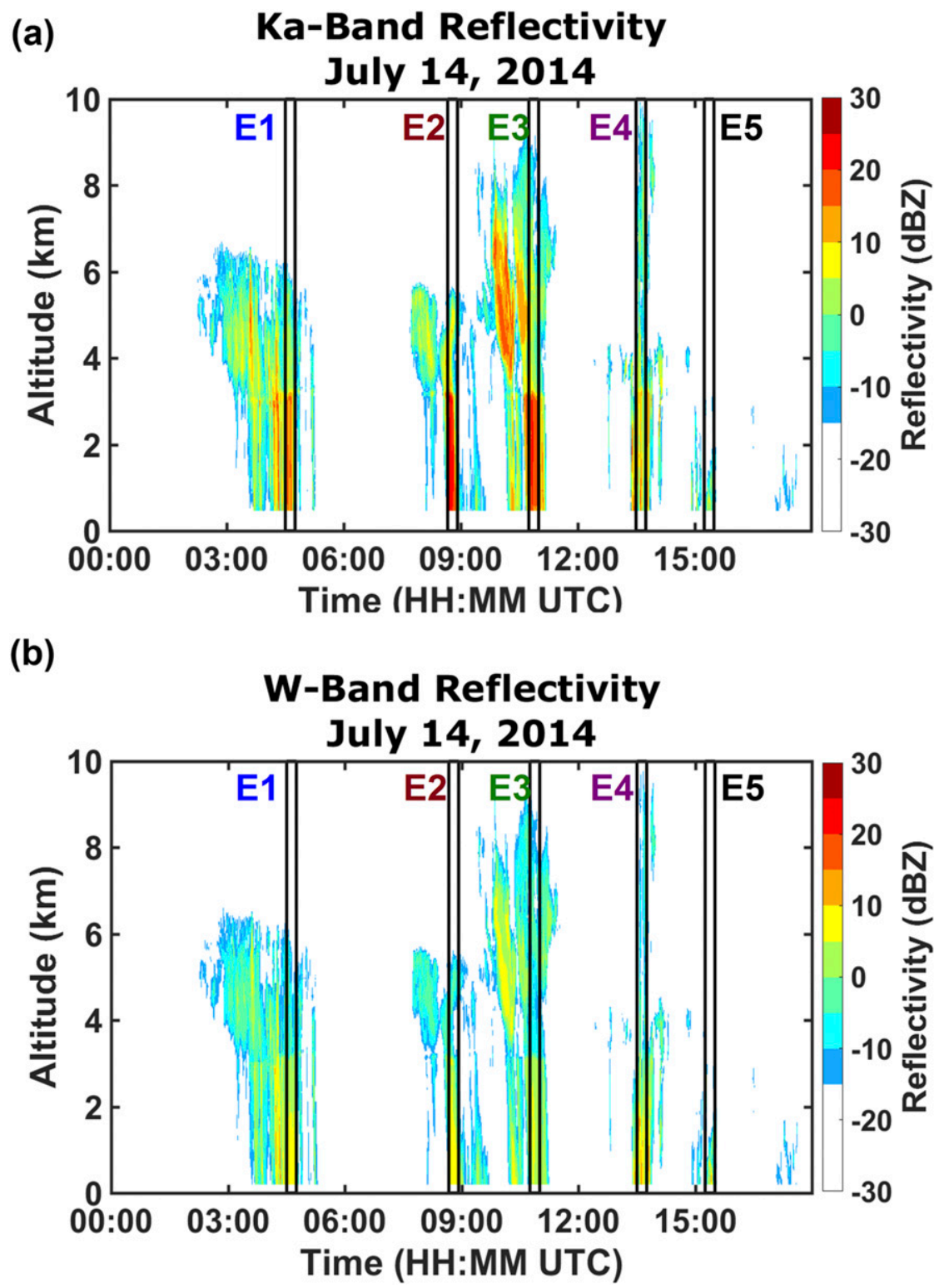

FIG. 8. Equivalent reflectivity factor of (a) Ka-ZR and (b) MWACR observed at ARM TMP on $14 \mathrm{Jul}$ 2014. Events considered for analysis (black boxes).

values from the end ( $t_{0}=15$ th minute) to the center of the window $\left(t_{0}=8\right.$ th minute). In the case of deep structure precipitation, events with rain rates greater than $8 \mathrm{~mm} \mathrm{~h}^{-1}$ are missed for the IPHEx IOP due to the use of $\mathrm{W}$ band for column calculations constrained by the field setup as discussed earlier, and the statistical sample is also small because of the lack of convective activity during the IPHEx IOP.

\section{b. ARM-TMP}

The observations at ARM TMP exhibit frequent "deep" nonconvective precipitation structures that are quite different compared to MV. Indeed, ARM TMP reflectivity profiles for deep structure events generally show enhanced reflectivity below the melting layer as a result of downward transport of ice from aloft, the socalled dark-band effect (see, e.g., Fig. 9 in Kollias and Albrecht 2005). For this reason, the altitude threshold to distinguish shallow and deep structure events is lower $\left(z_{c}=4 \mathrm{~km}\right)$. To account for the significant differences in precipitation physics, method 1 is applied here to the Ka-band reflectivity profiles up to $z_{1}=8.5 \mathrm{~km}$ and method 2 is computed using $z_{2}=1.5 \mathrm{~km}$ profiles for both $\mathrm{Ka}$ and $\mathrm{W}$ bands. The maximum elevation for 
(a)

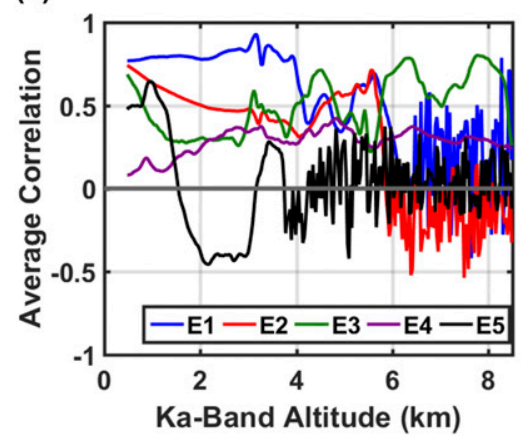

(b)

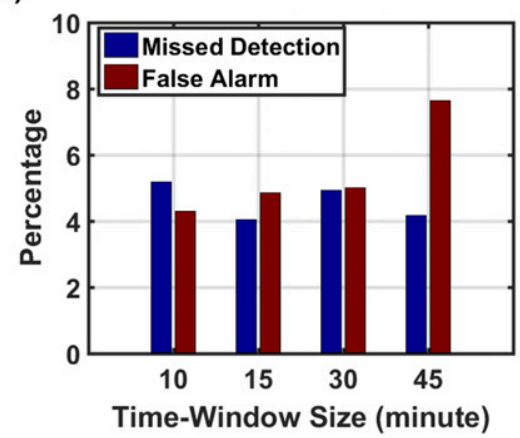

(c)

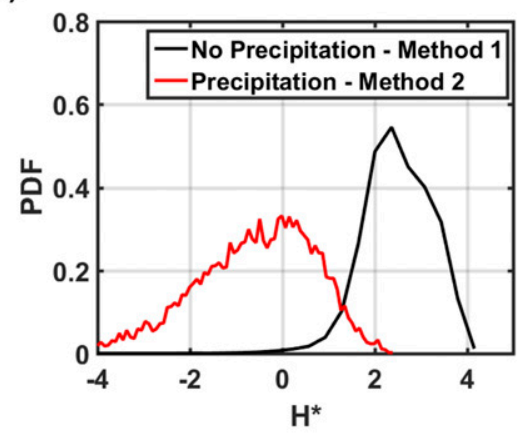

FIG. 9. (a) Method 1 average space-time correlation structure computed in step 2 of the algorithm for the five events highlighted in Fig. 8 (E1: 0430-0445 UTC, E2: 0840-0855 UTC, E3: 1045-1100 UTC, E4: 1330-1345 UTC, E5: 1515-1530 UTC) in Finland on 14 Jul 2014. (b) Comparison of MDR and FAR errors (expressed as a percentage of the total number of events) as a function of the time-window width. (c) PDF of the optimum (15 min) moving time window for the computation of VCS by the SRDC algorithm.

method 1 is selected based on the regional climatology of typical precipitation structure and clouds. Studies based on models and observations suggest that the maximum CTH closely depends on the height of the tropopause, and cloud tops in the high latitudes do not exceed altitudes of $8-9 \mathrm{~km}$ (Pan et al. 2010; Pan and Munchak 2011).

The 14 July 2014 event selected for detailed examination exhibits intermittent shallow and deep structure precipitation from 0300 to 1600 UTC (Fig. 8). Out of the five precipitation events (E1: 0430-0445 UTC, E2: 08400855 UTC, E3: 1045-1100 UTC, E4: 1330-1345 UTC, and E5: 1515-1530 UTC) detected, E2 and E5 are classified as shallow events. Space-time correlations for the individual events are displayed in Fig. 9a. Note how the average correlation pattern is quite similar to that obtained at MV (Fig. 5a), with smooth average correlation patterns for deep events below $z_{c}$ with a significant increase in reflectivity above. For the shallow events, there are large noisy oscillations in the correlation value above $z_{c}$.

The full ARM TMP dataset collected from 6 May 2014 until 11 September 2014 was used in the analysis corresponding to $10391 \mathrm{~min}$ of precipitation and 82352 min of nonrainy conditions. The next step was to find the appropriate time width for the moving window to optimize precipitation detection. Figure 9b summarizes the FAR and MDR errors, and Fig. 9c shows the PDFs of precipitating occurrence for optimal window sizes. Again, as in MV, a 15-min interval achieves the best error trade-off. The algorithm's application for the 14 July 2014 event with the 15-min window, and the variations of the VCS patterns obtained from method 1 and method 2 are shown in Fig. 10. Note that the FA and MD occur at either the beginning or the end of the event. The VCS values for method 1 show the expected

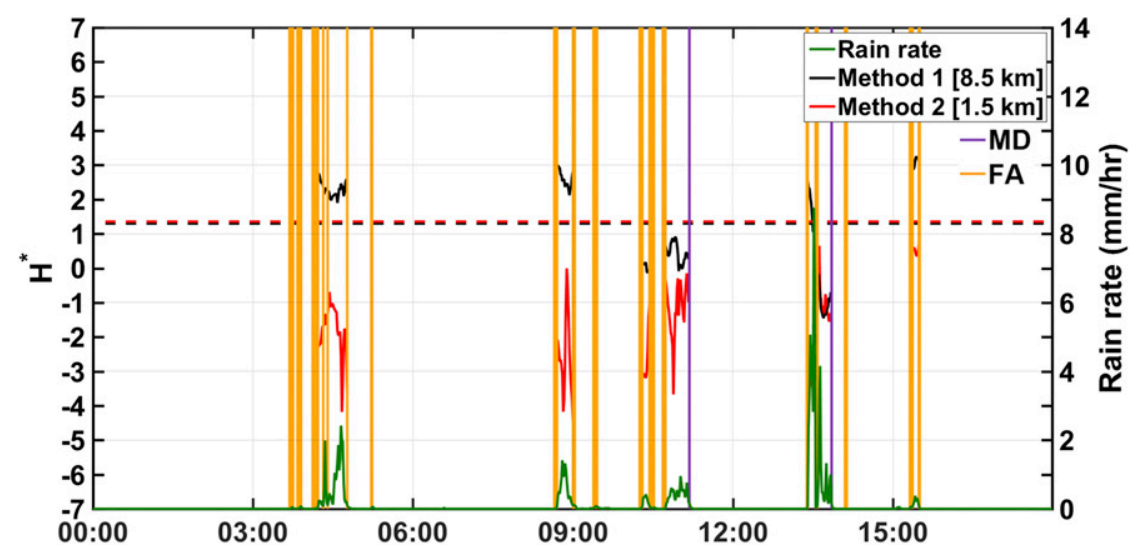

FIG. 10. Rain rate observed by 2DVD compared with VCS computed by methods 1 and 2 of the algorithm at ARM TMP on 14 Jul 2014. Threshold for precipitation detection (red dotted lines) and classification (black dotted lines). FA occurrences (orange lines) and MD occurrences (purples lines). 
(a)

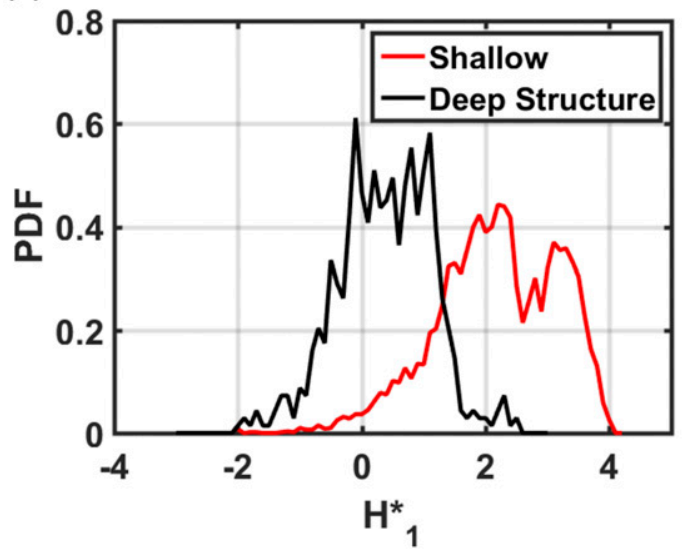

(b)

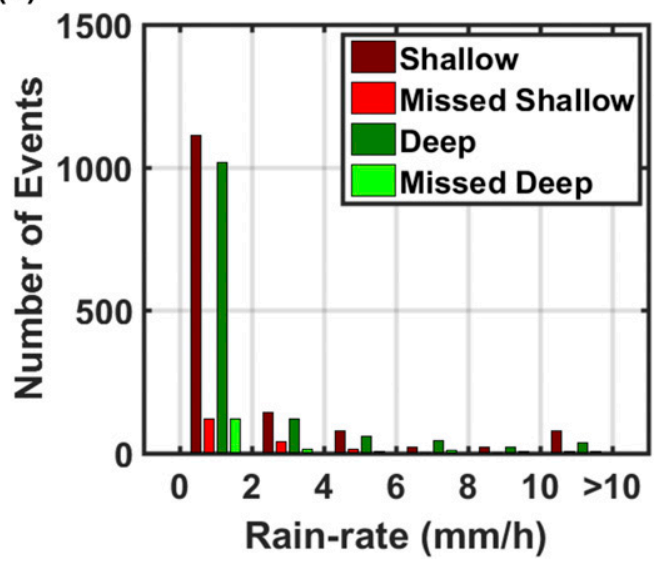

FIG. 11. (a) PDF of 15-min method 1 VCS values for classification of precipitation events at 1-min time scale. (b) Histogram of detection skill for different deep and shallow precipitation classes as a function of precipitation intensity during BAECC (May 2014-September 2014) at ARM TMP.

variations between clear-sky and deep structure precipitation events, while method 2 captures both shallow and deep precipitation as in MV.

When contrasting the precipitation detection PDFs obtained for ARM TMP (Fig. 9c) and MV (Fig. 5c), it is apparent that method $1 \mathrm{VCS}$ for clear-sky conditions is very different for the two locations. By contrast, the PDF of method 2 VCS at the ARM TMP site (Fig. 9c, red curve) closely resembles the PDF obtained for MV (Fig. 5c, red curve). The differences in $H_{1}^{*}$ PDFs of noprecipitation in MV and ARM TMP explain the different $H_{\text {det }}^{*}$ values for each location. This is attributed to the different operational setup of the Ka-band radars and differences in the vertical structure of light rainfall between the two hydrometeorological regimes as well.

The detection threshold for ARM TMP is $H_{\text {det }}^{*}=1.36$ with MDR and FAR of $3.9 \%$ and $4.5 \%$, respectively (Fig. 9c). A similar approach was followed for the precipitation classification, and the threshold for precipitation classification can be obtained from the PDFs in Fig. 11a $\left(H_{\text {cla }}^{*}=1.3\right)$. These thresholds are used to compute the contingency matrix shown in Table 2 . Shallow precipitation events are associated with higher

TABLE 2. Contingency table for precipitation detection and classification by SRDC methods 1 and 2 for profiles observed at ARM TMP.

\begin{tabular}{llrrr}
\hline \hline & \multicolumn{3}{c}{ Classified as } \\
\cline { 3 - 5 } & & $\begin{array}{c}\text { Deep } \\
(\%)\end{array}$ & $\begin{array}{c}\text { Shallow } \\
(\%)\end{array}$ & $\begin{array}{c}\text { No precipitation } \\
(\%)\end{array}$ \\
\hline \multirow{2}{*}{ Actual } & Deep & 91.7 & 8.2 & 0.1 \\
& Shallow & 17.0 & 78.4 & 4.6 \\
& No precipitation & 4.3 & 4.8 & 90.9 \\
\hline
\end{tabular}

ambiguity corresponding to a misclassification error of $17 \%$, whereas deep structure precipitation is misclassified $8 \%$ of the time.

A comparison among the histograms of precipitation intensity of actual and detected shallow and deep structure precipitation events is presented in Fig. 11b. Overall, the rain-rate PDF observed at ARM TMP is similar to MV with most of the observed precipitation being light rainfall with intensities below $2 \mathrm{~mm} \mathrm{~h}^{-1}$. Note that, if "dark band" cases were classified as shallow (not shown), then the VCS threshold value for classification is $H_{\mathrm{cla}}^{*}=1.5$, yielding higher misclassification errors of $7.3 \%$ and $16.1 \%$ for deep and shallow systems, respectively.

\section{c. GPM DPR and CloudSat CPR G-SDSU simulations}

The G-SDSU was used to simulate the radar equivalent reflectivity profiles observed by GPM DPR and CloudSat CPR at 1855 UTC 15 May 2014 in the SAM (Wilson and Barros 2015, 2017). Simulated reflectivity profiles along the coinciding satellite overpasses for the GPM DPR and CloudSat CPR are shown in Fig. 12. The maximum spatial distance between the GPM and CloudSat overpass pixels is $0.1926^{\circ}$, and over $94 \%$ of the pixels are collocated at the model resolution of $1.25 \mathrm{~km}$. The simulated GPM DPR (Ka band) and CloudSat CPR (W band) reflectivity profiles are the inputs into the SRDC algorithm toward evaluating the performance for satellite-based (nadir looking) radar at the same resolution. A terrain elevation mask was applied to the G-SDSU-simulated GPM-DPR and CloudSat-CPR profiles, and the analysis is conducted only for reflectivity profiles above the terrain. 


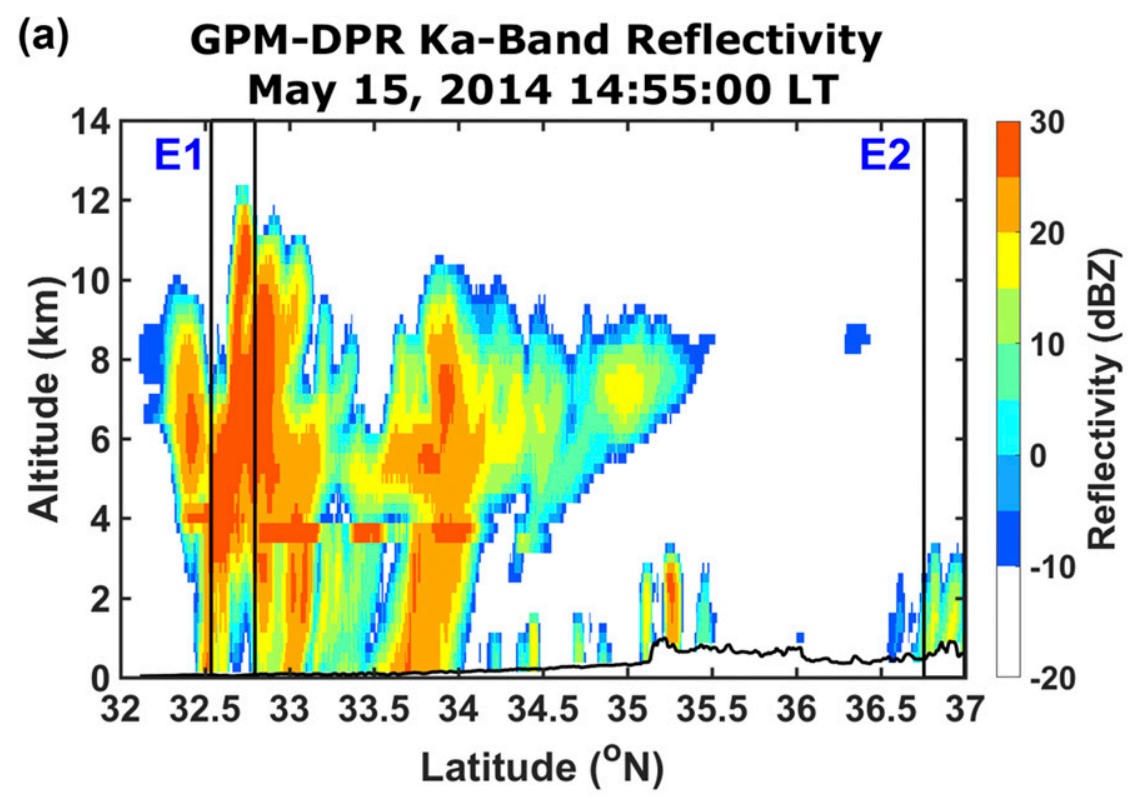

(b)

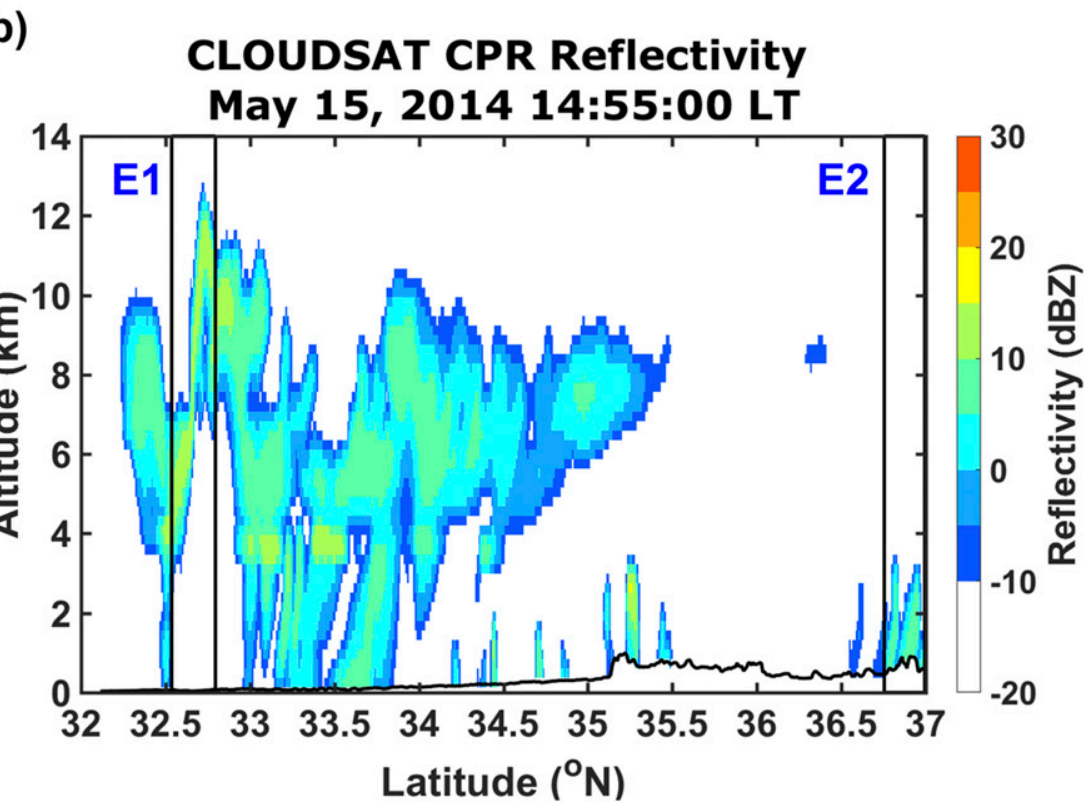

FIG. 12. Equivalent reflectivity factor simulated by the G-SDSU for a concurrent overpass of (a) GPM DPR Ka-band radar and (b) CloudSat CPR radar for 15 May 2014 event during IPHEx. Events E1 and E2 considered for analysis (black boxes).

The simulated reflectivity profiles for GPM DPR and CloudSat CPR exhibit deep and shallow precipitation structures with heavy and light rainfall, respectively. Note the difference between the downward-looking perspective from satellite-based sensors and the upward-looking perspective in the case of ground-based sensors (MV, TMP, and SGP) is well illustrated by the severe attenuation of simulated CloudSat CPR reflectivity in the lower troposphere for the deep convective event with heavy rainfall between $32.5^{\circ}$ and $33^{\circ} \mathrm{N}$.
Attenuation artifacts are still present in the case of the convective rainfall between $32.5^{\circ}$ and $33^{\circ} \mathrm{N}$ (E1), but not so for the light rainfall event between $36.5^{\circ}$ and $37.5^{\circ} \mathrm{N}(\mathrm{E} 2)$.

The simulated reflectivity profiles were input into the SRDC algorithm using a spatial moving average window width of five consecutive grid points (spatial length of $6 \mathrm{~km}$ ) to calculate the correlation between the two frequencies along the CloudSat daytime overpass trajectory-that is the algorithm applied here by 
(a)

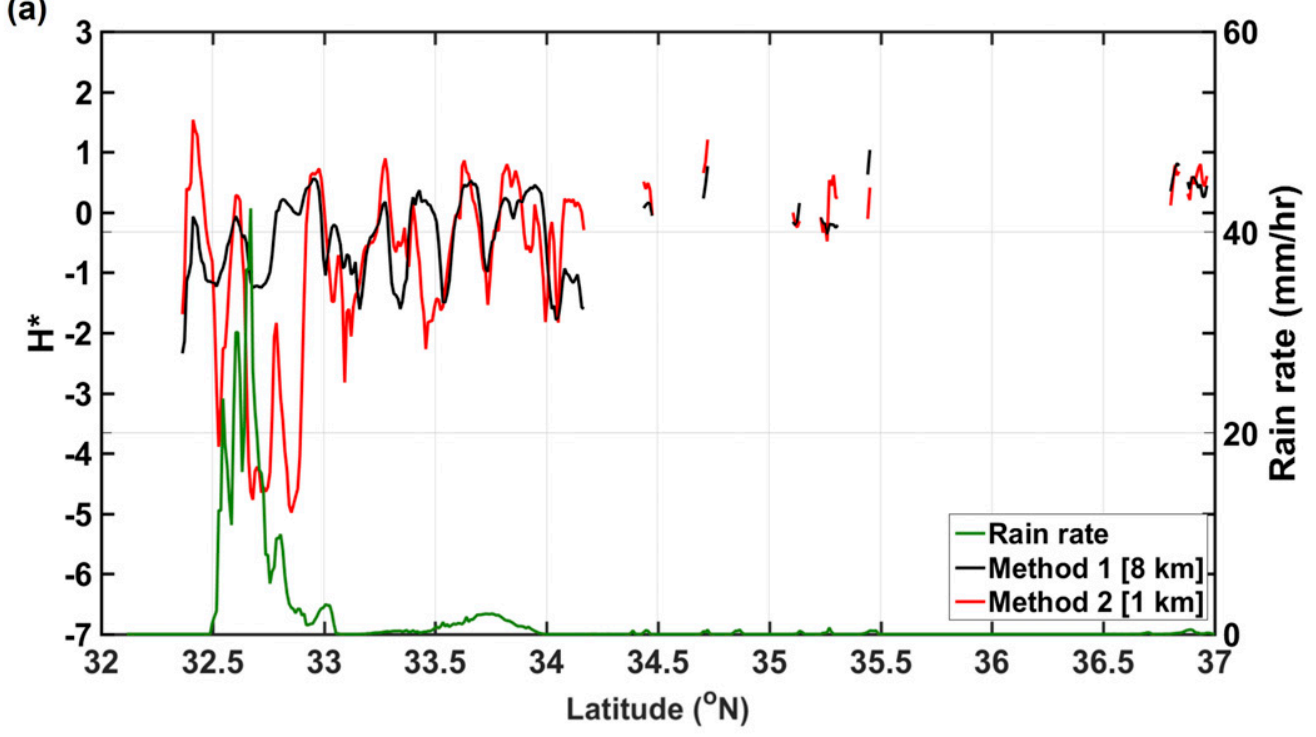

(b)

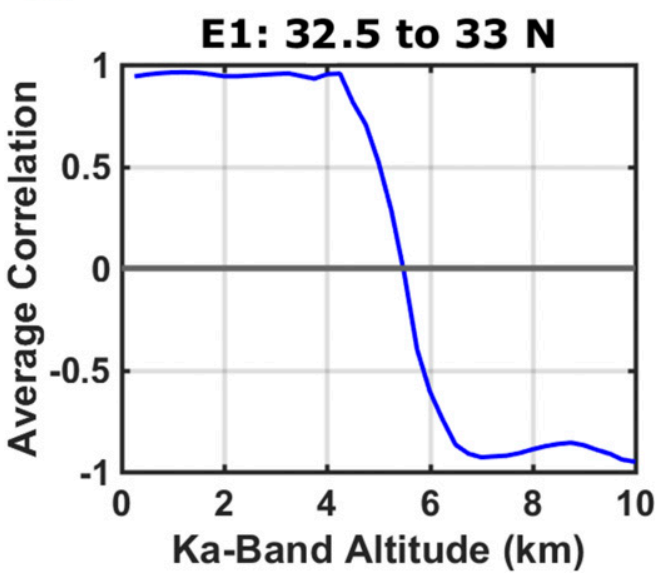

(c)

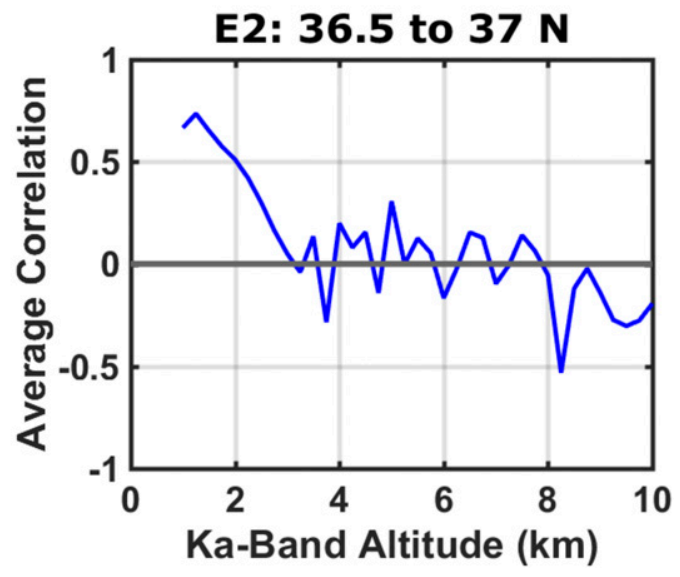

FIG. 13. (a) Rain rate simulated by WRF compared with 15-min VCS computed by SRDC methods 1 and 2 for the 15 May 2014 event. Method 1 average correlation profile computed from the space-time correlation DFC, where (b) E1: $32.5^{\circ}-33^{\circ} \mathrm{N}$ and (c) E2: $36.5^{\circ}-37^{\circ} \mathrm{N}$. E1 is a deep precipitation event, while E2 is a shallow light rainfall event with precipitation depth below $4 \mathrm{~km}$. Average correlation curves for these events show different behavior and zerocrossing altitudes consistent with different precipitation structures.

trading local time for space along the satellite overpass, with the pixel number along the overpass tract used as the spatial coordinate. Figure 13 shows the comparison of low-level (method 2) and column VCS (method 1). The G-SDSU does not simulate ground clutter artifacts that are present in the satellite-based observational datasets. Thus, the low-level height for method 2 is taken as $1 \mathrm{~km}$ AGL, which is the active depth of lowlevel seeder-feeder processes in the region (Wilson and Barros 2014, 2015, 2017; Duan et al. 2015); to capture the attenuation effects at high frequencies (e.g., CPR), the depth of the column for method 1 is taken as $8 \mathrm{~km}$ AGL. Indeed, the impact of CPR attenuation is apparent in the large negative values of low-level VCS for the cases of heavy rainfall (from left to right until latitude $34^{\circ} \mathrm{N}$ ). Beyond $34^{\circ} \mathrm{N}$ latitude, shallow rainfall is captured by the method 2 VCS (note the feature between $36.5^{\circ}$ and $37^{\circ} \mathrm{N}$ ). The detection and classification thresholds were not computed for this limited case study (an extensive OSSE study would be required for statistical robustness). Nevertheless, applying the zero-crossing criterion to the method $1 \mathrm{av}-$ erage correlation to identify the active depth of rainfall yields results that are consistent with the ground-based observations, as shown in Figs. 13b and 13c for E1 and $\mathrm{E} 2$, respectively. This case study is indicative of the 

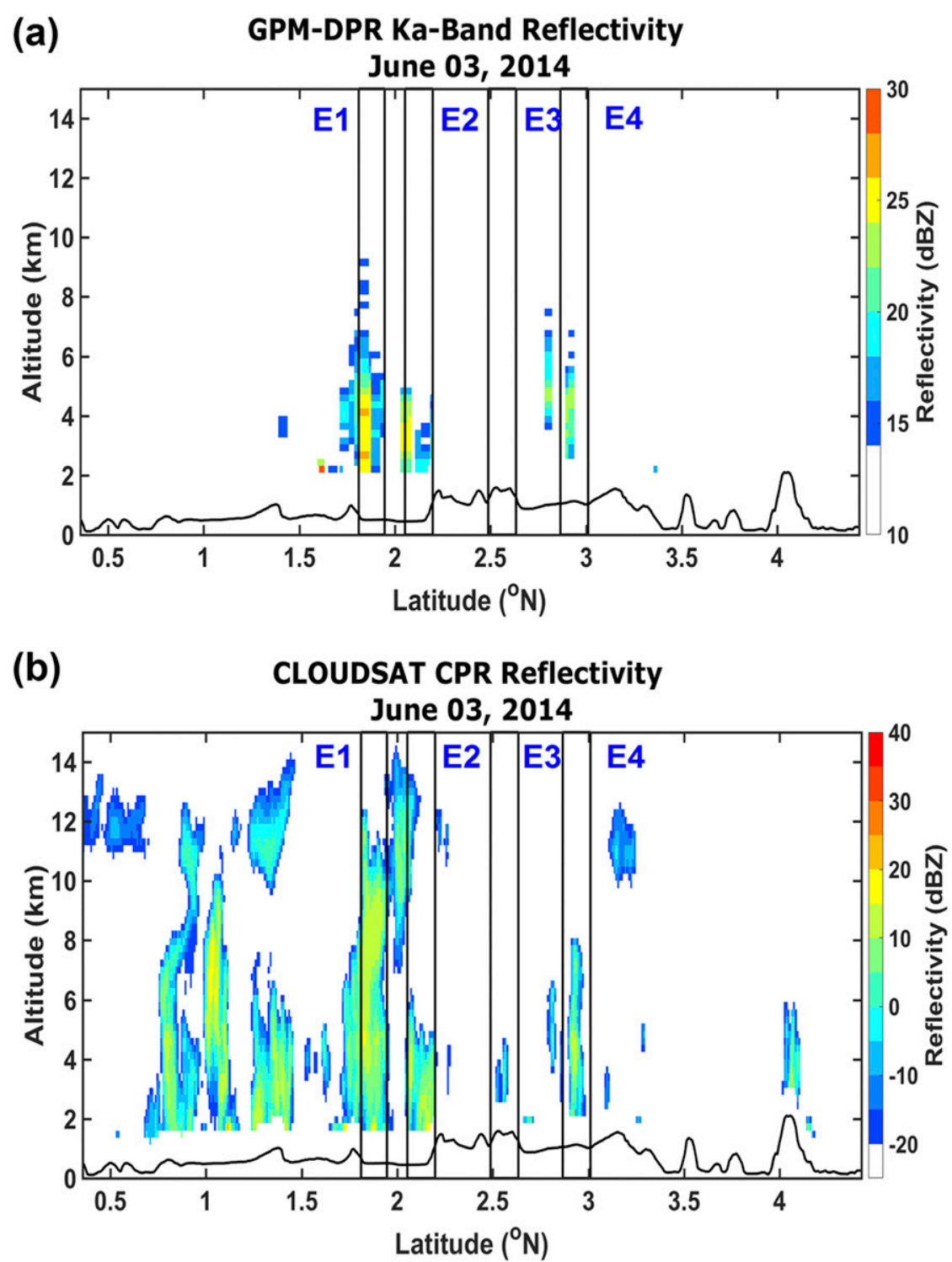

FIG. 14. Equivalent reflectivity factor observed by concurrent overpasses of (a) GPM DPR Ka-band radar and (b) CloudSat CPR radar from the combined 2BCSATDPR product on 3 Jun 2014 over Borneo (115 $\mathrm{E}$ ). Events considered for the analysis (black boxes).

potential applicability of the SRDC algorithm at least for nadir- or near-nadir-looking satelliteborne radar systems. It also highlights the need to further characterize the impact of attenuation at high frequencies, as well as the need for large datasets to establish operational metrics, such as the VCS thresholds estimated for the groundbased applications. The performance of the algorithm using actual GPM DPR and CloudSat CPR observations is illustrated next.

\section{d. GPM DPR and CloudSat CPR observations}

Reflectivity profiles observed by CloudSat CPR and GPM DPR Ka band on 3 June 2014 over complex terrain in Borneo $\left(115^{\circ} \mathrm{E}\right)$ from the Kapuas Mountains to the South China Sea (see Fig. 1 for map) were extracted to demonstrate the application of the SRDC algorithm to observations from space-based platforms (Fig. 14). Because the reflectivity profiles are affected strongly by ground clutter, the digital elevation model (DEM) mask included in the CloudSat CPR products was used to remove the radar bins in the lowest $2 \mathrm{~km}$ AGL. The GPM DPR Ka-band radar overpass coincides with the CloudSat CPR between $1.5^{\circ}$ and $3.5^{\circ} \mathrm{N}$, and all the pixels are within the resolution of GPM DPR products $(5 \mathrm{~km})$. The time difference between the two overpasses is approximately $7 \mathrm{~min}$. Missing 
(a)

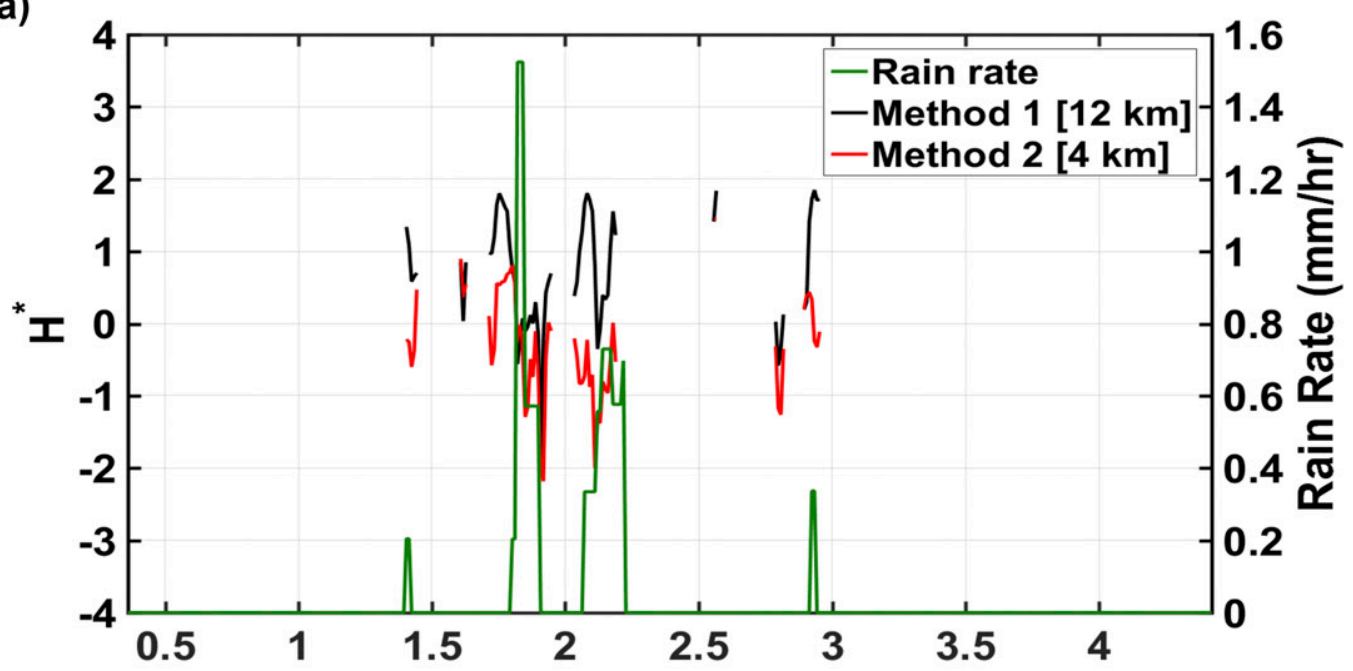

(b)

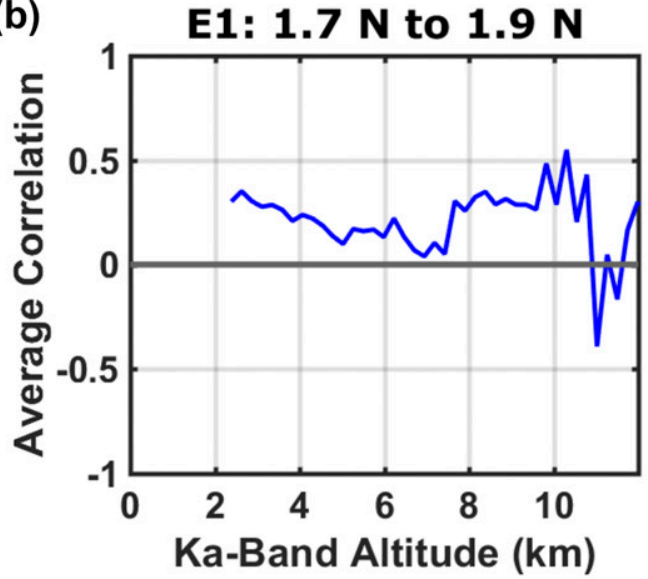

(d)

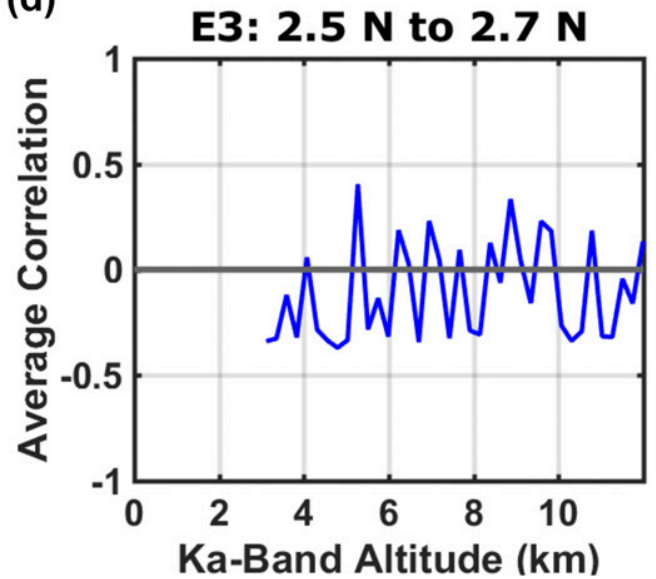

(c)

E2: $2 \mathrm{~N}$ to $2.2 \mathrm{~N}$

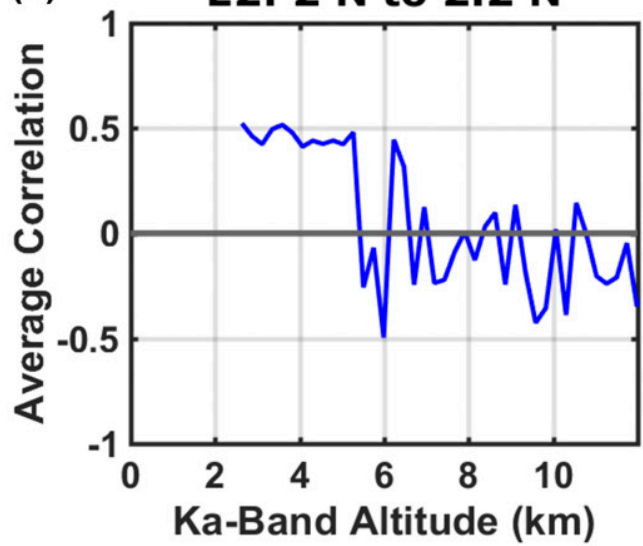

(e)

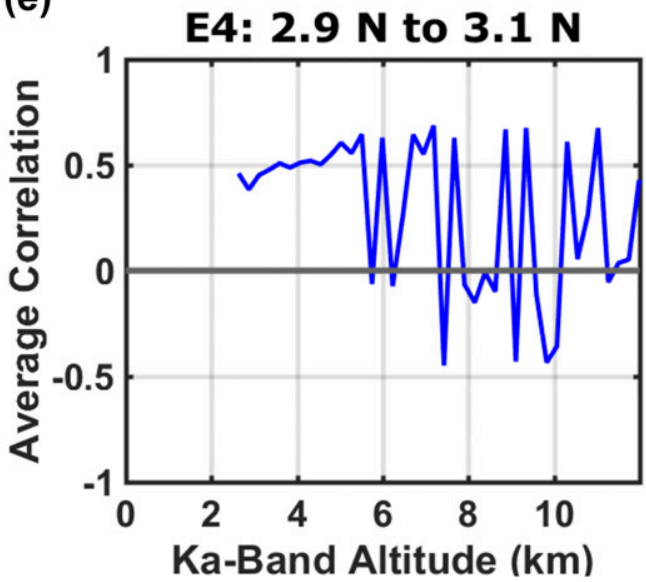

FIG. 15. (a) VCS functions computed by SRDC methods 1 and 2 for the reflectivity profiles and rain rates from the GPM DPR 2A product. Method 1 average correlation profile computed from the space-time correlation computed in step 2 of the algorithm, where (b) E1: $1.7^{\circ}-2^{\circ} \mathrm{N}$, (c) E2: $2^{\circ}-2.2^{\circ} \mathrm{N}$, (d) E3: $2.5^{\circ}-2.7^{\circ} \mathrm{N}$, and (e) E4: $2.9^{\circ}-3.1^{\circ} \mathrm{N}$. E1 and E4 are deep structure events, E2 is a shallow event, and E3 is a no precipitation event. Note the change in the shape and altitude of first zero-crossing points of the correlation profiles based on the structure of precipitation. 
TABLE 3. Detection and classification VCS thresholds used in the SRDC algorithm for MV, ARM TMP, and ARM SGP. The value in the parentheses is for the detection threshold when "dark band" cases are classified as shallow precipitation.

\begin{tabular}{lll}
\hline \hline Location & $H_{\text {det }}^{*}$ & \multicolumn{1}{c}{$H_{\text {cla }}^{*}$} \\
\hline MV & 1.91 & 2.76 \\
ARM TMP & 1.36 & $1.3(1.5)$ \\
ARM SGP & 1.3 & 1.5 \\
\hline
\end{tabular}

values above $9 \mathrm{~km}$ AGL in the 2ADPR V04A HS product and low-level values affected by ground clutter were replaced with a Gaussian random variable of mean 0 and variance 0.01 . The ground clutter values in the CloudSat CPR reflectivity product were replaced by a Gaussian random variable of mean -25 and variance 0.01 . The mean values for the missing value correction of GPM DPR and CloudSat CPR were chosen based on the minimum detectable threshold of the instruments. Low-level VCS (method 2) values are computed for $4-\mathrm{km}$ profiles of the two satellite products. Column VCS (method 1) values are calculated using maximum heights of 12 and $4 \mathrm{~km}$ AGL for GPM DPR and CloudSat CPR, respectively. The spatial window chosen for the analysis is approximately $10 \mathrm{~km}$, corresponding to 10 CloudSat CPR and two GPM DPR coaligned pixels. The joint temporal evolution of the VCS and the precipitation rate estimates derived from Ka-band radar (2ADPR V04A HS product) is examined next.

The deep structure events observed between $1.7^{\circ}$ and $1.9^{\circ} \mathrm{N}(\mathrm{E} 1)$, and $2.9^{\circ}$ and $3.1^{\circ} \mathrm{N}(\mathrm{E} 4)$ are captured by both method 1 and method 2, while the shallow structure between $2^{\circ}$ and $2.2^{\circ} \mathrm{N}$ (E2) is captured only by method 2 as expected (Fig. 15a). As in the previous case study, the detection and classification thresholds are not computed because of the lack of enough samples for robust statistics. Note how the CloudSat CPR observes a shallow cloud system between $2.5^{\circ}$ and $2.7^{\circ} \mathrm{N}$ (E3) that is missed by the GPM DPR Ka band. The method 1 (column) average correlation patterns for the four highlighted events (E1-E4) are presented in Figs. 15b-e. Like for ground-based observations at MV and ARM TMP, the first zero crossing of the average correlation is a robust criterion to determine the depth of precipitation structures from space. Indeed, the SRDC detects most of the precipitation features observed where and when concurrent observations exist, despite differences in instrument sensitivity and observing geometry. Exploratory applications of the SRDC using Ka-band MS and $\mathrm{Ku}$-band NS instead of Ka-band HS yielded similar results (not shown) though the zero-crossing height is different, consistent with expectations for the storm-top height in Toyoshima et al. (2015).

\section{Summary and conclusions}

This study presents a dual-frequency radar algorithm for shallow rainfall detection and classification (SRDC). The algorithm aims to provide an efficient way to combine multiple radar observations, taking advantage of different operating frequencies to characterize the vertical structure of precipitation using an integrated VCS metric to describe the evolution of the space-time correlation structure of radar reflectivity profiles. The SRDC formulation is applicable to any pair of frequencies with contrasts in attenuation and scattering behavior, such as, for example, replacing Ka band with either $\mathrm{Ku}$, or $\mathrm{X}$, or $\mathrm{C}$ band. Indeed, performance should be expected to improve using frequencies lower than $\mathrm{Ka}$ band. The focus here is on $\mathrm{W}$ and Ka bands because of data availability constraints only.

The SRDC was tested using collocated ground-based W- and Ka-band radar reflectivity observations with a focus on warm rainfall events at the surface only. Snowfall at the ground was not included because the vertical structure of reflectivity (and the underlying microphysics) for snow events above and below $0^{\circ} \mathrm{C}$ is out of the scope of this work. Method 1 and method 2 VCS are used to detect and classify precipitation events. However, the detection and classification thresholds can be estimated with confidence only when large collocated datasets at different frequencies are available. The behavior of the first zero crossover is illustrates that method 1 and method 2 work as intended and are immune to the exact $z_{c}$ location and the correlation variability. Further, over a given geographic region, when the algorithm is first applied, the $z_{c}$ can be used to aid in the classification until robust VCS statistics are determined. The algorithm was applied first to radar profiles obtained from the IPHEx IOP ground validation campaign in MV with successful detection of precipitation $99 \%$ of the time. Further, the algorithm performed well in distinguishing between shallow and deep precipitation in the complex terrain of the SAM, even with column VCS calculated using W-band radar instead of Ka-band radar, which exhibits less attenuation at low levels because of setup constraints.

An independent evaluation was conducted at the ARM TMP in Finland. Furthermore, a third independent application of the SRDC was carried out at the ARM SGP in the central United States. A detailed description of the ARM SGP application is provided in section S2 of the supplemental material, including Figs $\mathrm{S} 1-\mathrm{S} 4$. The SGP is representative of the midlatitude continental plains, while the TMP site was located close to and in between land-water margins and coastlines. Consequently, the maximum vertical range considered 
(a)

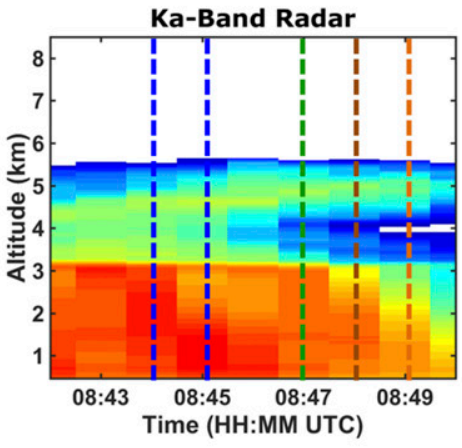

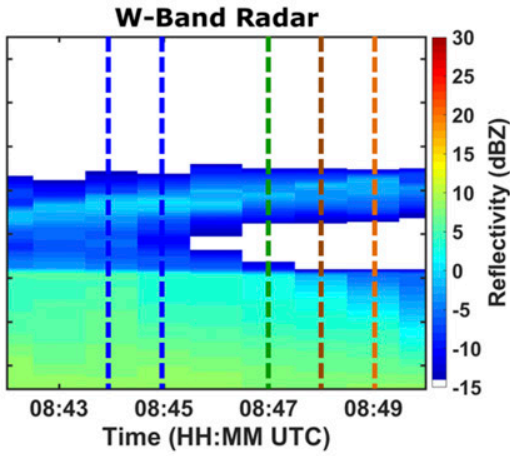

(b)
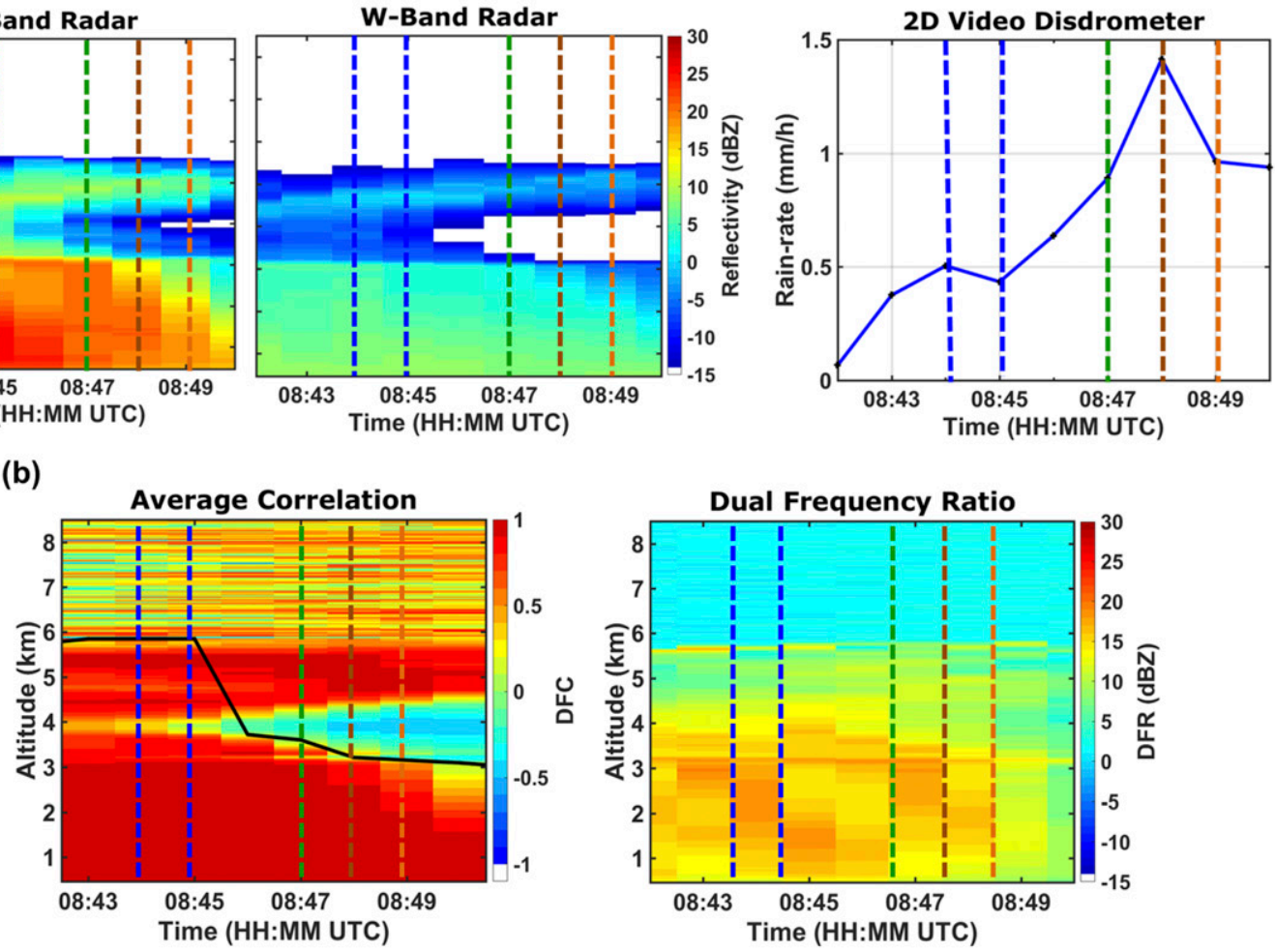

(c)

DEEP

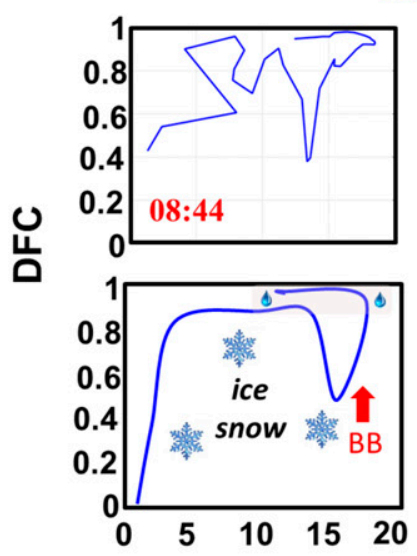

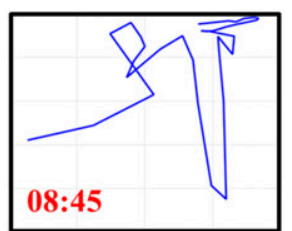

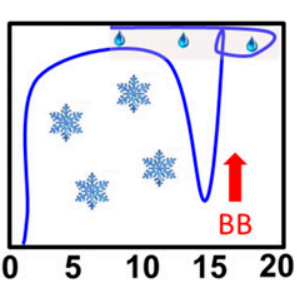

TRANSITION
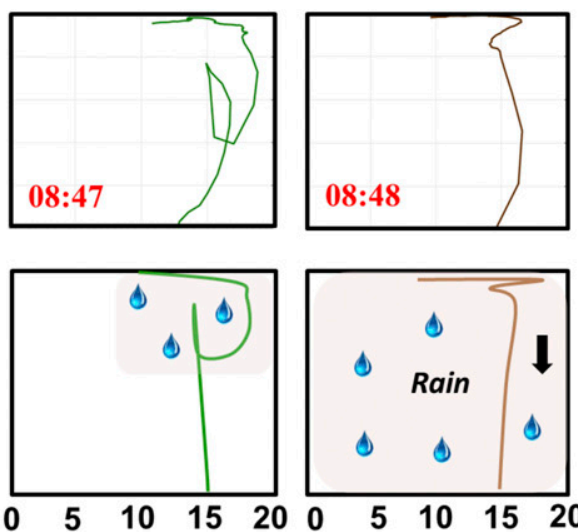

SHALLOW

\section{DFR (dBZ)}

FIG. 16. (a) (left to right) Observed Ka- and W-band reflectivity, and surface rainfall rate at ARM TMP on 14 Jul 2014 , including a transition from deep structure to shallow structure rainfall (see also Fig. 8). (b) (left to right) DFC and DFR profiles computed from the observations. (c) (top) Temporal evolution of DFC-DFR trajectories at the times marked by the dashed lines of the same color in (a) and (b). (bottom) Schematic generalization of evolution of the relationship between DFR and DFC at select times from (two leftmost panels) the deep structure stage of the event as the bright-band effect increases and the drop size distribution broadens near the surface, (middle) through the transition phase without bright-band signature and heavy surface rainfall, and (two rightmost panels) into the shallow structure stage of the event as it weakens and vertical depletion of a large drop becomes apparent. In (a), profiles in the deep structure (blue line), transition (green line), and shallow (brown line) structure stages of the events.

for the computation of column VCS (method 1$)$ is quite different, reflecting climatic differences in precipitation climatology. Nonetheless, the MDR and FAR obtained from the precipitation detection algorithm for both
TMP and SGP agree with each other and are approximately $4.5 \%$ and $0.5 \%$, respectively. The classification algorithm provides better classification skill for deep structures compared to shallow events for MV and 
ARM TMP. However, the opposite is true in the SGP case, although only three cases ( $42 \mathrm{~min}$ of rainfall) were available at the time when the study was conducted. The detection and classification threshold values using W band as support for the column correlation calculations (method 1$)$ are very close in both TMP and SGP (Table 3 ), when both sensors were operating with a similar set up and in contrast to MV, which supports the general applicability of the algorithm.

The SRDC physical basis can be further examined in light of the phase-space trajectories of concurrent dualfrequency correlation (DFC) and dual-frequency ratio 9DFR; $\left.z_{\mathrm{Ka}}(\mathrm{dB} Z)-Z_{\mathrm{W}}(\mathrm{dB} Z)\right]$ below the first zerocrossing height. This is illustrated in Fig. 16 using 8 min of observations during the 14 July 2014 event at the ARM TMP site (see Fig. 8). Ka- and W-band reflectivity profiles exhibit the signature of deep structure precipitation, including mixed-phase processes in the first $3 \mathrm{~min}$ (0843-0845 UTC) followed by a transition to shallow structure warm rainfall in the next $2 \mathrm{~min}$ (Fig. 16a). The DFC and DFR profiles are shown in Fig. $16 \mathrm{~b}$ followed by an analysis of DFC-DFR relationships in Fig. 16c. In Fig. 16c, left panels, note the strengthening of the bright band (red arrows) and its corresponding signature in the DFC-DFR phase space (low DFC and high DFR excursion in the bottom-right-hand corner), both of which are accompanied by intensification of low-level rainfall captured by the DFR protrusion at high DFC values (top-right corner of the phase space). As the event evolves into shallow structure precipitation, the bright band disappears in the middle panels, the low-level protrusion deepens initially as a result of large melted hydrometeors from above, and eventually recedes (black arrows) as the column is selectively depleted of large raindrops first. The right panels show how the DFR progressively decreases (and DSD narrows) from the surface upward (from high to low DFC). The DFC-DFR analysis supports therefore the notion of VCS thresholds ( $H_{\mathrm{det}}^{*}$ and $H_{\mathrm{cla}}^{*}$ ) that should be precipitation regime dependent, not location dependent. Nevertheless, fingerprints of regional weather require adaptive VCS thresholds to correct for artifacts that may introduce ambiguity errors. For example, the presence of darkband effects in the TMP observations prompted the lowering of the classification VCS threshold with significant improvement in the SRDC skill statistics. Other relevant examples include the attenuation at high frequencies for heavy rainfall in the tropics along with "bright band" artifacts.

Proof-of-concept demonstrations from space (i.e., looking downward) were conducted using simulated and observed GPM DPR Ka-band and CloudSat CPR W-band radar reflectivity profiles for concurrent overpasses.
Results show good potential for detecting deep and shallow rainfall structures, and for identifying the active depth of precipitation using the first zero crossing of the DFC. To generalize the application of SRDC to satellite-based observations, detection, and classification, we envision the implementation of a global Bayesian learning framework to estimate SRDC parameters toward achieving optimal detection and classification leveraging ground validation sites where available.

Acknowledgments. The authors are grateful to Dr. Robert Meneghini and four anonymous reviewers for their valuable comments and suggestions. This research was supported by Grant NASA NNX16AM28G to the second author and a NASA Earth System Science Fellowship Grant NNX16AO10H to the first author. The algorithm code is available from the authors upon request. MRR and W-band reflectivity profiles from MV can be obtained from the NASA Global Hydrology Resource Center DAAC (doi:10.5067/GPMGV/IPHEX/MRR/DATA201; doi:10.5067/GPMGV/IPHEX/WBAND/DATA101). The ARM TMP and ARM SGP data were downloaded from the ARM Climate Research Facility data archive. MWACR and KaZR data at ARM TMP were compiled by B. Isom et al. (doi:10.5439/1150242) and the 2DVD data were compiled by M. Bartholomew (doi:10.5439/1025315). W-SACR and Ka-ZR data at ARM SGP were compiled by B. Isom et al. (doi:10.5439/1150290) and ORG data were compiled by D. Cook et al. (doi:10.5439/1046212).

\section{REFERENCES}

Balestrino, A., A. Caiti, and E. Crisostomi, 2007: A classification of nonlinear systems: An entropy based approach. Chem. Eng. Trans., 11, 119-124.

Barros, A. P., 2013: Orographic precipitation, freshwater resources, and climate vulnerabilities in mountainous regions. Vulnerability of Water Resources to Climate, F. Hossain, Ed., Vol. 5, Climate Vulnerability: Understanding and Addressing Threats to Essential Resources, Academic Press, 57-78, doi:10.1016/B978-0-12-384703-4.00504-9.

— M. Joshi, J. Putkonen, and D. W. Burbank, 2000: A study of the 1999 monsoon rainfall in a mountainous region in central Nepal using TRMM products and rain gauge observations. Geophys. Res. Lett., 27, 3683-3686, doi:10.1029/2000GL011827.

_- and Coauthors, 2014: NASA GPM-Ground validation: Integrated Precipitation and Hydrology Experiment 2014 science plan. NASA Tech. Rep., 64 pp., doi:10.7924/G8CC0XMR.

Denis, A., and F. Cremoux, 2002: Using the entropy of curves to segment a time or spatial series. Math. Geol., 34, 899-914, doi:10.1023/A:1021302922108.

Duan, Y., A. M. Wilson, and A. P. Barros, 2015: Scoping a field experiment: Error diagnostics of TRMM precipitation radar estimates in complex terrain as a basis for IPHEx2014. Hydrol. Earth Syst. Sci., 19, 1501-1520, doi:10.5194/hess-19-1501-2015.

Feng, Z., S. A. McFarlane, C. Schumacher, S. Ellis, J. Comstock, and N. Bharadwaj, 2014: Constructing a merged cloud-precipitation 
radar dataset for tropical convective clouds during the DYNAMO/AMIE experiment at Addu Atoll. J. Atmos. Oceanic Technol., 31, 1021-1042, doi:10.1175/JTECH-D-13-00132.1.

Hou, A. Y., and Coauthors, 2014: The Global Precipitation Measurement Mission. Bull. Amer. Meteor. Soc., 95, 701-722, doi:10.1175/BAMS-D-13-00164.1.

Houze, R. A., Jr. 1993: Climate Dynamics. International Geophysics Series, Vol. 53, Academic Press, 573 pp.

- 2012: Orographic effects on precipitating clouds. Rev. Geophys., 50, 3683-3686, doi:10.1029/2011RG000365.

Iguchi, T., T. Kozu, R. Meneghini, J. Awaka, and K. Okamoto, 2000: Rain-profiling algorithm for the TRMM precipitation radar. J. Appl. Meteor., 39, 2038-2052, doi:10.1175/1520-0450(2001)040<2038: RPAFTT $>2.0 . \mathrm{CO} ; 2$.

- S. Seto, R. Meneghini, N. Yoshida, J. Awaka, and T. Kubota, 2015: GPM/DPR Level-2 algorithm theoretical basis document. NASA/ JAXA Tech. Rep., 72 pp., https://pmm.nasa.gov/sites/default/files/ document_files/ATBD_GPM_DPR_n3_dec15.pdf.

Kollias, P., and B. Albrecht, 2005: Why the melting layer radar reflectivity is not bright at $94 \mathrm{GHz}$. Geophys. Res. Lett., 32 , L24818, doi:10.1029/2005GL024074.

-, E. E. Clothiaux, M. A. Miller, B. A. Albrecht, G. L. Stephens, and T. P. Ackerman, 2007: Millimeter-wavelength radars: New frontier in atmospheric cloud and precipitation research. Bull. Amer. Meteor. Soc., 88, 1608-1624, doi:10.1175/BAMS-88-10-1608.

Liao, L., R. Meneghini, and A. Tokay, 2014: Uncertainties of GPM DPR rain estimates caused by DSD parameterizations. J. Appl. Meteor. Climatol., 53, 2524-2537, doi:10.1175/JAMC-D-14-0003.1.

Marzano, F. S., L. Roberti, S. D. Michele, A. Mugnai, and A. Tassa, 2003: Modeling of apparent radar reflectivity due to convective clouds at attenuating wavelengths. Radio Sci., 38, 1002, doi:10.1029/2002RS002613.

Matsui, T., and Coauthors, 2013: GPM satellite simulator over ground validation sites. Bull. Amer. Meteor. Soc., 94, 1653-1660, doi:10.1175/BAMS-D-12-00160.1.

Mead, J. B., A. L. Pazmany, S. M. Sekelsky, and R. E. McIntosh, 1996: Millimeter-wave radars for remotely sensing clouds and precipitation. IGARSS '96: Remote Sensing for a Sustainable Future, Vol. 3, IEEE, 1553-1555, doi:10.1109/IGARSS.1996.516728.

Pan, L. L., and L. A. Munchak, 2011: Relationship of cloud top to the tropopause and jet structure from CALIPSO data. J. Geophys. Res., 116, D12201, doi:10.1029/2010JD015462.

_ , and Coauthors, 2010: The stratosphere-troposphere analyses of regional transport 2008 experiment. Bull. Amer. Meteor. Soc., 91, 327-342, doi:10.1175/2009BAMS2865.1.

Petäjä, T., 2013: Science plan: Biogenic Aerosols-Effects on Clouds and Climate (BAECC). Dept. of Energy Tech. Rep. DOE/SC-ARM-13-024, 36 pp.
Prat, O. P., and A. P. Barros, 2010: Assessing satellite-based precipitation estimates in the Southern Appalachian Mountains using rain gauges and TRMM PR. Adv. Geosci., 25, 143-153, doi:10.5194/adgeo-25-143-2010.

, — - and C. R. Williams, 2008: An intercomparison of model simulations and VPR estimates of the vertical structure of warm stratiform rainfall during TWP-ICE. J. Appl. Meteor. Climatol., 47, 2797-2815, doi:10.1175/2008JAMC1801.1.

Short, D. A., and K. Nakamura, 2000: TRMM radar observations of shallow precipitation over the tropical oceans. J. Climate, 13, 4107-4124, doi:10.1175/1520-0442(2000)013<4107: TROOSP $>2.0 . \mathrm{CO} ; 2$.

Sindhu, K. D., and G. S. Bhat, 2013: Comparison of Cloudsat and TRMM radar reflectivities. J. Earth Syst. Sci., 122, 947-956, doi:10.1007/s12040-013-0316-9.

Stephens, G. L., and Coauthors, 2008: CloudSat mission: Performance and early science after the first year of operation. J. Geophys. Res., 113, D00A18, doi:10.1029/2008JD009982.

Tao, W.-K., and Coauthors, 2009: The Goddard multi-scale modeling system with unified physics. Ann. Geophys., 27, 3055-3064, doi:10.5194/angeo-27-3055-2009.

Toyoshima, K., H. Masunaga, and F. A. Furuzawa, 2015: Early evaluation of $\mathrm{Ku}$ - and Ka-band sensitivities for the Global Precipitation Measurement (GPM) Dual-Frequency Precipitation Radar (DPR). SOLA, 11, 14-17, doi:10.2151/ sola.2015-004.

Turk, J., 2016: CloudSat-GPM coincidence dataset, version 1C. NASA Algorithm Theoretical Basis Doc., 18 pp., https://pmm. nasa.gov/sites/default/files/document_files/CSATGPM_COIN_ ATBD.pdf.

Wilson, A. M., and A. P. Barros, 2014: An investigation of warm rainfall microphysics in the southern Appalachians: Orographic enhancement via low-level seeder-feeder interactions. J. Atmos. Sci., 71, 1783-1805, doi:10.1175/ JAS-D-13-0228.1.

— , and — 2015: Landform controls on low level moisture convergence and the diurnal cycle of warm season orographic rainfall in the Southern Appalachians. J. Hydrol., 531, 475-493, doi:10.1016/j.jhydrol.2015.10.068. , and - 2017: Orographic land-atmosphere interactions and the diurnal cycle of low level clouds and fog. J. Hydrometeor., 18, 1513-1533, https://doi.org/10.1175/JHM-D-16-0186.1.

Zafar, B. J., and V. Chandrasekar, 2004: Classification of precipitation type from space borne precipitation radar data and 2D wavelet analysis. IGARSS 2004: 2004 IEEE International Geoscience and Remote Sensing Symposium, Vol. 5, IEEE, 3570-3573, doi:10.1109/ IGARSS.2004.1370482. 